\title{
Viewpoints
}

\section{The Ubiquitinated Axon: Local Control of Axon Development and Function by Ubiquitin}

\author{
${ }^{\circledR}$ Maria J. Pinto, ${ }^{1}{ }^{\circledR}$ Diogo Tomé, ${ }^{1,2}$ and ${ }^{\circledR}$ Ramiro D. Almeida ${ }^{1,2}$ \\ ${ }^{1}$ Center for Neuroscience and Cell Biology, University of Coimbra, Coimbra, 3004-504, Portugal, and ${ }^{2}$ Institute of Biomedicine, Department of \\ Medical Sciences, University of Aveiro, Aveiro, 3810-193, Portugal
}

Ubiquitin tagging sets protein fate. With a wide range of possible patterns and reversibility, ubiquitination can assume many shapes to meet specific demands of a particular cell across time and space. In neurons, unique cells with functionally distinct axons and dendrites harboring dynamic synapses, the ubiquitin code is exploited at the height of its power. Indeed, wide expression of ubiquitination and proteasome machinery at synapses, a diverse brain ubiquitome, and the existence of ubiquitin-related neurodevelopmental diseases support a fundamental role of ubiquitin signaling in the developing and mature brain. While special attention has been given to dendritic ubiquitin-dependent control, how axonal biology is governed by this small but versatile molecule has been considerably less discussed. Herein, we set out to explore the ubiquitin-mediated spatiotemporal control of an axon's lifetime: from its differentiation and growth through presynaptic formation, function, and pruning.

Key words: axons; presynaptic terminal; ubiquitin; ubiquitin-proteasome system; neuronal disorders

\section{Introduction}

Ubiquitin functions in cells as a small tag bound in an extremely selective manner to target proteins. Cells use ubiquitination as a method to modify proteins: either transiently, by altering localization, activity, and signaling of the tagged protein, or permanently, by dispatching the protein for degradation in the so-called ubiquitin-proteasome system (UPS) or in lysosomes. Ubiquitination is therefore a strategy cells use for regulation at the local level in a temporal and target-specific manner. Such regulation is particularly suitable for cells, such as neurons, which have highly compartmentalized functions. Indeed, axons and dendrites could not be more distinct in their function and protein composition, despite being intimately and functionally connected by synapses. This necessitates the ability of different, but highly regulated, local mechanisms to change protein content and hence function, ultimately securing proper synaptic connectivity. In addition, the unique polarized morphology of neurons, with long axons and plastic synapses undergoing constant changes in their proteome, impose a challenge on the local mechanisms governing proteostasis. It is therefore unsurprising that neuronal ubiquitin signaling is of utmost importance for

Received Aug. 31, 2020; revised Jan. 15, 2021; accepted Jan. 22, 2021.

M.J. Pinto's present address: Institut de Biologie de l'École Normale Supérieure, École Normale Supérieure, Institut National de la Santé et de la Recherche Médicale, Centre National de la Recherche Scientifique, Paris Sciences et Lettres Research University, Paris, 75005, France.

This work was supported by "la Caixa" Foundation, (ID 100010434) and FCT, I.P. under the agreement LCF/PR/HP20/52300001, by Fundação para a Ciência e a Tecnologia, I.P., under projects UIDB/04501/2020, UID/NEU/04539/2019 and PTDC/SAU-NEU/104100/2008; and Grants SFRH/BD/51196/ 2010 to M.J.P. and SFRH/BD/139368/2018 to D.T.

The authors declare no competing financial interests.

Correspondence should be addressed to Ramiro D. Almeida at ramirodalmeida@gmail.com or Maria J. Pinto at mjoanagp@gmail.com.

https://doi.org/10.1523/JNEUROSCI.2251-20.2021

Copyright $\odot 2021$ the authors proper brain function. This importance is underscored by the fact that ubiquitin-positive aggregates are present in nearly all neurodegenerative diseases (Perry et al., 1987; Lowe et al., 1988; Davies et al., 1997) and mutations in ubiquitin-related machinery underlie the pathogenesis of several neurodevelopmental diseases (Matsuura et al., 1997; Leroy et al., 1998; Morrow et al., 2008; Ramser et al., 2008; Paemka et al., 2015; Nguyen et al., 2016).

At the postsynaptic level, the UPS contributes to synaptic remodeling by providing activity-dependent control of key postsynaptic proteins, such as scaffolds and receptors (Colledge et al., 2003; Ehlers, 2003; Kato et al., 2005; Saliba et al., 2007; Hamilton et al., 2012; Shin et al., 2012; Widagdo et al., 2015). Indeed, proteasomes are recruited to dendritic spines on depolarization (Bingol and Schuman, 2006) to sculpt the content of a synapse consonantly to its activity status (Ehlers, 2003). As a result, the UPS is crucial for the establishment of synaptic plasticity, making it essential for memory formation and retrieval (Artinian et al., 2008; Lee et al., 2008; Jarome et al., 2011; Jarome and Helmstetter, 2013; Ferrara et al., 2019). In addition to postsynaptic proteins, the presynaptic proteome is regulated by ubiquitin-dependent mechanisms. Several axonal proteins have been identified as ubiquitin substrates (Franco et al., 2011; $\mathrm{Na}$ et al., 2012), suggesting an involvement of the UPS in axonal development and presynaptic function. Although knowledge about ubiquitin signaling in axons has accumulated in recent years, a comprehensive compilation of these studies is still lacking. In this review, we propose to unravel how, when, and where ubiquitin signaling is exploited throughout the early and mature life of axons.

\section{Ubiquitin signaling}

Ubiquitin is a highly conserved small protein with 76 amino acids that has the unusual property of being covalently attached 
A

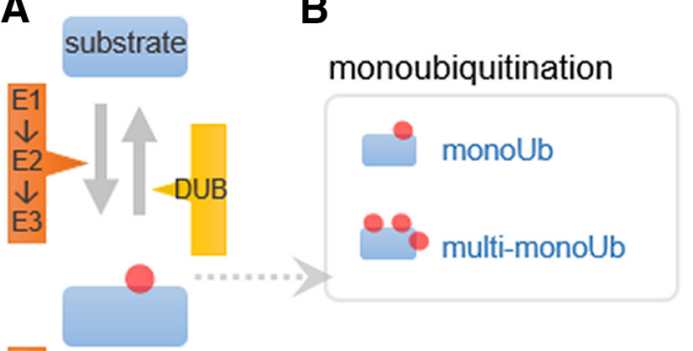

C

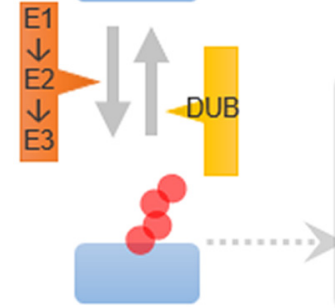

polyubiquitination

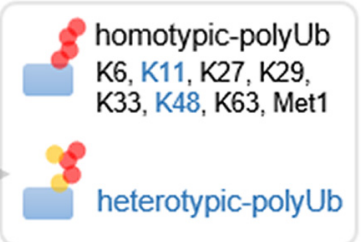

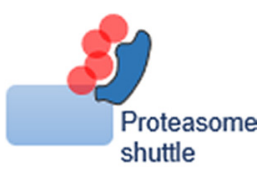

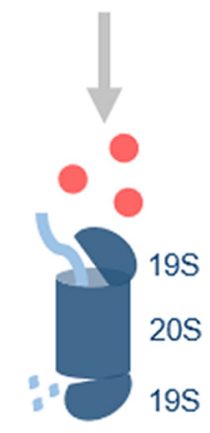

Figure 1. Ubiquitin signaling. $\boldsymbol{A}$, Attachment of ubiquitin moieties to naked substrates is promoted by a cascade of enzymes (E1 ubiquitin-activating enzyme, E2 ubiquitin-conjugating enzyme, and E3 ubiquitinligase) and counteracted by deubiquitinases (DUB) that trim bound ubiquitin. Several rounds of ubiquitination can lead to formation of polyubiquitin chains. $\boldsymbol{B}$, Different topologies of ubiquitin signals on substrates. Substrates can be found in a monoubiquitinated state [single ubiquitin (monoUb) or multiple single ubiquitins (multi-monoUb)] or harboring polyubiquitin chains (polyUb). In homotypic chains, linkage between ubiquitin molecules occurs in the same lysine $(K)$ residue, whereas heterotypic chains contain mixed linkages. For monoubiquitination and polyubiquitination, blue represents ubiquitin signals that may function as a tag for proteasome clearance. C, Proteins harboring a degradation tag are directed to the proteasome by shuttles, deubiquitinated, unfolded, and degraded within the 205 catalytic core.

to other proteins. The attachment of ubiquitin to a protein, known as ubiquitination, constitutes a type of post-translational modification that can alter several properties of the target protein, such as its stability, structure, function, localization, and interaction with partners (Komander and Rape, 2012). Ubiquitin is a highly stable protein that adopts a compact $\beta$-grasp fold with an exposed carboxy terminal tail that forms an isopeptide bond with lysine (K) residues of a protein substrate. In addition, ubiquitin itself has seven lysine residues that can all serve as attachment sites for additional ubiquitin molecules. As a consequence, cellular proteins can be found in a monoubiquitinated or polyubiquitinated form, the latter resulting from the polymerization of ubiquitin chains on the first substrate-conjugated ubiquitin (Fig. $1 A, B$ ). Because in ubiquitin all seven lysine residues, as well as the first methionine, are able to accept another ubiquitin, different homotypic chains linked via K6, K11, K27, K29, K33, K48, K63, and Met1 can be attached to substrates. In the rat brain, polyubiquitin chains are expressed in the following ascending order: K29, K27, K33, K6, K11, K63 and K48 ( $~ 0.05 \%, 0.5 \%, 8 \%, 9 \%, 15 \%, 29 \%$, and $37 \%$, respectively) (Na et al., 2012). Ubiquitin signaling is further diversified by the attachment of single ubiquitin molecules to multiple sites of a protein (multi-monoubiquitination) and formation of heterotypic chains containing mixed linkage types (Peng et al., 2003; Xu et al., 2009; Komander and Rape, 2012) (Fig. 1B). In the mouse brain, the majority of ubiquitin is in the free, unconjugated form, whereas only $35 \%$ and $5 \%$ of total ubiquitin is present, respectively, as monoubiquitin and polyubiquitin modifications on substrates (Kaiser et al., 2011). Thus, cells keep a considerably large pool of readily available free ubiquitin, suggesting that substrates can be rapidly ubiquitinated on need. The small pool of conjugated polyubiquitin further suggests that cells can rapidly respond to new intracellular substrate-conjugated ubiquitin signals, rather than requiring substrates to keep their ubiquitinated state for long periods of time.

Assembly of ubiquitin chains is performed by a three-step enzymatic cascade involving an E1 ubiquitin-activating enzyme, an E2 ubiquitin-conjugating enzyme, and an E3 ubiquitin-ligase. The first step comprises activation of ubiquitin by the E1 enzyme in an ATP-dependent manner. Activated ubiquitin is transferred to the E2 enzyme, which forms a complex with a substrate-carrying E3, ultimately leading to the covalent binding of ubiquitin to a lysine residue of the target protein (Pickart, 2001) (Fig. 1A). Importantly, E3 ligases are the key specifiers of protein ubiquitination, mostly because of their recognition of substrates by specific proteinprotein interactions.

In general, E3 ligases are classified based on their E2 interaction domain: an interesting new gene (RING) finger domain, a U-box motif, or a homologous to E6-AP carboxyterminus (HECT) domain. While RING and U-box E3 ligases [e.g., RING finger protein (RNF) family and C-terminus of Hsp70interacting protein, respectively] catalyze the direct transfer of ubiquitin from the E2 enzyme to the substrate, HECT E3 ligases [e.g., neuronal precursor cell expressed developmentally downregulated 4 (Nedd4)] produce an additional HECT-ubiquitin intermediate before forwarding ubiquitin to the substrate (Zheng and Shabek, 2017). In the recently discovered hybrid system of RING-between-RING E3 ligases (e.g., Parkin), the first RING transfers ubiquitin to the second RING domain before its relocation to the final substrate (Wenzel et al., 2011; Walden and Rittinger, 2018). RING E3 ligases can either function as a single protein or as a multisubunit complex. Examples of the latter are the Skp1-Cullin-F-box (SCF) and the anaphase promoting (APC) complex. These are multisubunit E3 ligases that rely on a substrate-recognizing protein, an F-box protein in the SCF complex, and Cdh1 or Cdc20 in the APC complex.

The reversibility of ubiquitin signaling is accomplished by deubiquitinases capable of removing ubiquitin molecules from substrates (Fig. 1A). Deubiquitinases can either fully deubiquitinate a substrate or edit polyubiquitin chains, thus redirecting a substrate's fate after the initial ubiquitination. They also have a prime role in disassembling unanchored ubiquitin chains and removing ubiquitin from proteasome substrates (Komander et al., 2009). Thus, in addition to their role in ensuring correct ubiquitination of substrates, they are essential for the maintenance of the cellular free ubiquitin pool, a prerequisite for proper cell function and viability (Swaminathan et al., 1999; Kimura et al., 2009), in particular nervous system development (Osaka et al., 2003; Chen et al., 2009; Ryu et al., 2014).

The diverse ubiquitin messages on proteins are decoded by proteins that recognize ubiquitin signals, interpret them, and generate a biochemical output in the cell. These proteins are generally termed ubiquitin-binding proteins, and they contain specialized ubiquitin-binding domains that bind transiently and noncovalently to either monoubiquitin or polyubiquitin. They may exhibit relative or absolute selectivity for different types of ubiquitin chains (Husnjak and Dikic, 2012). A quick and self-explanatory example are proteasome shuttle factors that predominantly bind to proteins bearing a K48 polyubiquitin chain and deliver them to the proteasome for degradation (Verma et al., 2004; Elsasser and Finley, 2005) (see The UPS). 
In summary, cells possess all the required molecular machinery for coordinated assembly and editing of ubiquitin signals on proteins, as well as for their decoding and translation into different cell responses. As we will discuss later, axons possess all these elements, and thus can use ubiquitin signaling in an autonomous and local manner.

\section{Functions of ubiquitination}

The diverse patterns of ubiquitination found on different proteins (Fig. $1 B$ ) suggests that ubiquitination has a wide range of functions. The best documented of these is the role of K48 ubiquitin chains in tagging proteins for disposal by the proteasome. Although a few other roles have been suggested, the functional significance of most forms of conjugated ubiquitin species is still unknown.

The UPS. Proteasome-mediated degradation is the most wellknown outcome of ubiquitin signaling, classically associated with K48 ubiquitin chains, more precisely to substrates harboring a ubiquitin chain with four or more ubiquitin moieties (Thrower et al., 2000). The UPS is the major degradative pathway of soluble short-lived proteins in cells; and, as a result, it is involved in essentially every cellular event. In neurons, it is of utmost importance for neuronal development, function, and plasticity (Bingol and Sheng, 2011).

The macromolecular structure that degrades polyubiquitinated proteins is the $26 \mathrm{~S}$ proteasome, which is formed by a barrel-shaped 20S catalytic core particle and the $19 \mathrm{~S}$ regulatory particle (Fig. 1C). In brief, the $19 \mathrm{~S}$ specifically selects and guides target proteins to the $20 \mathrm{~S}$ proteolytic chamber. Equipped with an array of functionally distinct subunits, the 19S traps polyubiquitinated substrates, detaches ubiquitin chains, and generates ATP to unfold the protein and open the 20S. Once inside, substrates are cleaved by the inwardly facing catalytic subunits of the $20 \mathrm{~S}$ particle (Kish-Trier and Hill, 2013; Tanaka, 2013). Instrumental for effective function of the UPS are proteasome shuttle factors, such as Rad23, Dsk2, and Ddi1, that collect ubiquitinated substrates and deliver them to the proteasome for their final breakdown (Verma et al., 2004; Elsasser and Finley, 2005).

Recently, substantial data have been gathered demonstrating that K48 ubiquitin is not the sole tag for proteasome clearance. Remarkably, all polyubiquitin chains, except for K63, accumulate in cells shortly after proteasome inhibition (Xu et al., 2009), as well as in the brain of a $26 \mathrm{~S}$ conditional $\mathrm{KO}$ mouse (Bedford et al., 2011), thus indirectly suggesting the involvement of these polyubiquitin chains in the UPS. Indeed, the E3 complex APC is a master supplier of K11 ubiquitin chains to mitotic regulators, thereby sentencing them to degradation (Jin et al., 2008). The repertoire of proteolytic signals also includes substrates harboring heterotypic chains, one or multiple single ubiquitins, and nonubiquitinated substrates (Murakami et al., 1992; Boutet et al., 2007; Kravtsova-Ivantsiv et al., 2009; C. Liu et al., 2017) (Fig. $1 B)$. This broad range of degradation tags may confer on the UPS higher specificity and plasticity in its selection of targets to eliminate. For example, it is conceivable that K48 tags function in cells as constitutive signals for degradation, while noncanonical ubiquitin signals are exploited to fulfill specific cellular needs.

Proteasome-unrelated outcomes of the ubiquitin code. Protein ubiquitination is not always interpreted in cells as a proteasome tag. Indeed, it may alter the targeted protein and the concomitant cellular pathway in myriad ways. For instance, ubiquitination has been shown to regulate the endocytic pathway and lysosome degradation (Piper et al., 2014), DNA repair (Jackson and
Durocher, 2013), and the NF- $\kappa \mathrm{B}$ regulatory pathway (Deng et al., 2000; Wang et al., 2001; Windheim et al., 2008).

In the endocytic pathway, membrane proteins are internalized into endosomes, from which they can be sorted into late endosomes. Subsequent fusion of late endosomes with lysosomes leads to proteolysis. Both internalization at the plasma membrane and sorting to late endosomes are governed by ubiquitination, mostly by K63 ubiquitin chains, single or multiple monoubiquitin moieties on substrates (Piper et al., 2014). In this manner, ubiquitin can spatiotemporally control the signaling downstream of activated surface receptors, such as members of the receptor tyrosine kinase family (see Table 2).

Ubiquitin's mode of action in DNA repair and the NF- $\kappa$ B signaling are slightly different. Herein, ubiquitin chains act as recruiters of molecular machinery to specific cellular locations. For instance, DNA lesions are first detected by proteins that, in part through K63 ubiquitin chains or monoubiquitination, recruit and activate additional components of the DNA repair machinery (Jackson and Durocher, 2013).

Ubiquitination can also alter, either directly or indirectly, several properties of the tagged protein itself, including activity, location, or propensity to interact with partners (Laub et al., 1998; Li et al., 2003; DuPont et al., 2009; Sasaki et al., 2011; Baker et al., 2013; Wang et al., 2018). A good example of the latter is the K29 ubiquitination of axin, a scaffold for Wnt signaling, by E3 Smad ubiquitination regulatory factor 1 (Smurf1) (Fei et al., 2013). Axin interacts with the coreceptor LRP5/6 of the synaptogenic protein Wnt; however, on addition of a K29 ubiquitin tag, this interaction is disrupted and Wnt signaling is repressed (Fei et al., 2013).

Overall, the diverse world of possible ubiquitin tags (Fig. 1B), along with the ever-broadening list of possible functions (Swatek and Komander, 2016), suggests that ubiquitin is involved in a horde of cellular events that have so far not been investigated. Thus, there is a great unexplored potential of ubiquitin signaling. In the coming sections, we propose to unveil the role of ubiquitin signaling in axons, the neuronal compartment that functions as the main dispatcher of neurotransmission.

\section{Ubiquitin and the proteasome in axons}

Brain functioning relies on effective connectivity between neurons, exquisitely complex cells that display a high degree of morphologic and functional polarity. During nervous system development, an ordered sequence of elaborate events leads to the establishment of short- or long-range axonal projections with numerous presynaptic terminals that are precisely connected to postsynaptic cells. Soon after a growing neurite acquires initial axonal characteristics (Yogev and Shen, 2017), the growing axon is guided by extracellular cues (Polleux and Snider, 2010; Stoeckli, 2018) to a precise spatial location where it encounters the receptive dendrites of its partner. Formation of a presynaptic terminal is then triggered and specified by soluble and cell adhesion factors (Pinto and Almeida, 2016). Later, synapses are strengthened and enlarged or pruned, mostly depending on their activity level (Riccomagno and Kolodkin, 2015). When mature and functional, presynaptic terminals mediate rapid and controlled release of neurotransmitters (Südhof, 2013).

In this section, we provide a chronological overview of ubiquitin-related events taking place in axons throughout the course of their development (sections Axon specification, Axon outgrowth, Axon guidance, and Presynapse formation) and in their mature form (sections Presynaptic function and Axonal self-destructive events). We hope this will provide a deep understanding 


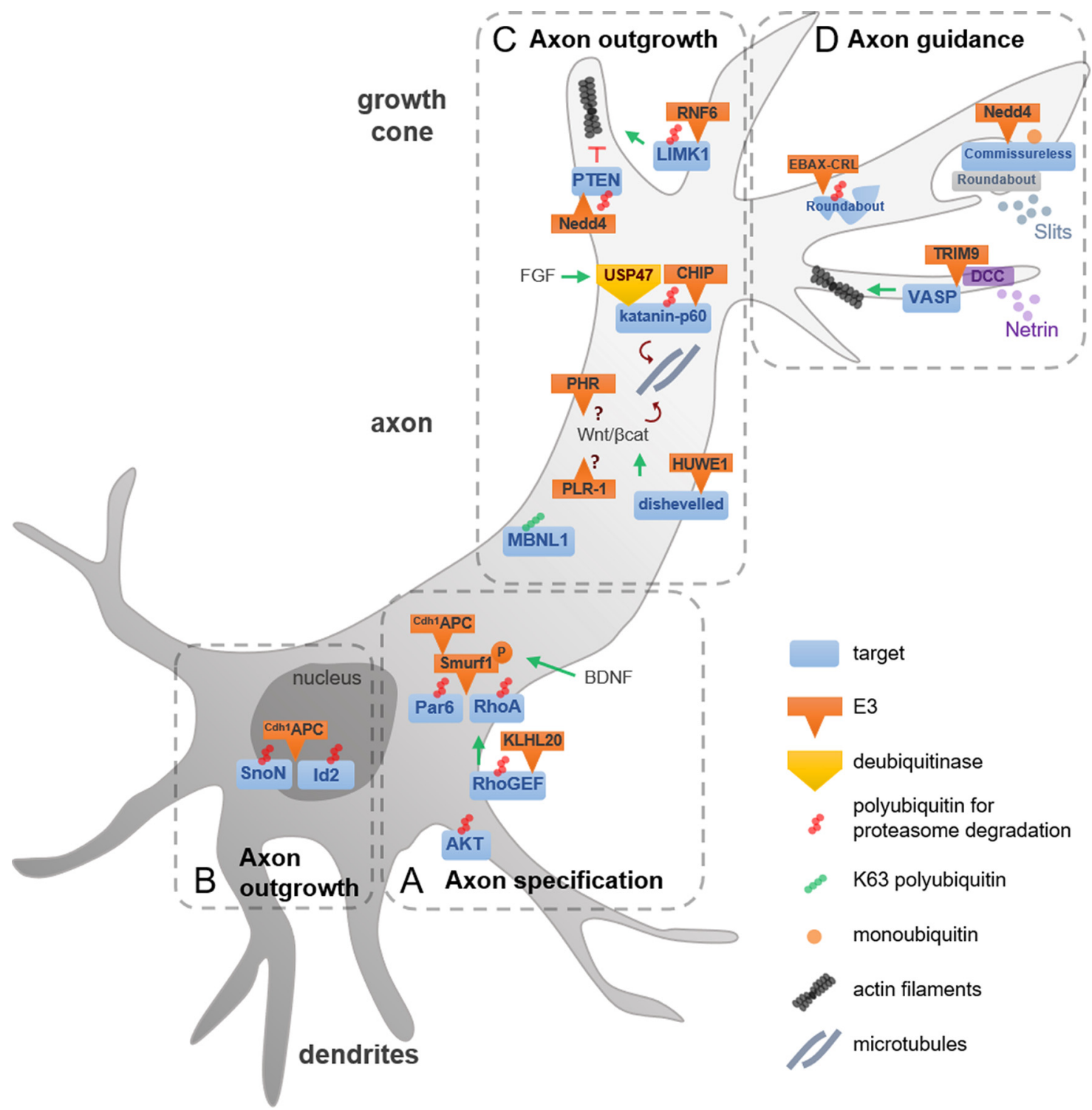

Figure 2. Molecular players in ubiquitin control of axon development. Local ubiquitin-mediated regulation occurs and supports all steps of axon morphogenesis, starting with the initial phase in which an axon gains its identity $(\boldsymbol{A}$, axon specification), and continuing as the axon grows $(\boldsymbol{B}, \boldsymbol{C}$, axon outgrowth) and navigates its way to its target $(\boldsymbol{D}$, axon guidance). Ubiquitin-targeted proteins (blue) and respective $\mathrm{E} 3$ ubiquitin ligases (orange) or deubiquitinases (yellow) are illustrated at their site of action. The type of ubiquitin chains involved is indicated. For complementary information, see Table 1. CHIP, C-terminus of Hsp70-interacting protein; DCC, deleted in colorectal cancer; EBAX-CRL, EBAX-type Cullin-RING; LIMK1, LIM kinase 1; RhoGEF, Rho guanine nucleotide exchange factor.

of ubiquitin-dependent mechanisms acting locally to govern axon development and function (Figs. 2, 3). To aid this endeavor, we provide a thorough description of the ubiquitination machinery and axonal targets involved (Table 1). We also provide a list of additional axonal proteins whose modulation by ubiquitin has been described, but not yet assigned a functional role in the axon (Table 2).

\section{Axon specification}

The characteristic morphology of the nerve cell stems partly from the polarization of its neurites (i.e., the formation of a single axon and multiple dendrites). A newborn neuron becomes polarized at an early stage of development, when one of several unspecified neurites acquires axonal characteristics. This is generally triggered by an external cue that creates asymmetric domains in the developing neuron by changing local protein content. This ultimately elicits major cytoskeletal rearrangements selectively favoring growth of the prospective axon (Yogev and Shen, 2017). The UPS contributes to the generation of this asymmetry by degrading specific proteins in a regulated spatiotemporal fashion (Fig. 2A; Table 1) (Yan et al., 2006; Cheng et al., 2011a; Lin et al., 2011). Axon growth-promoting and -inhibiting proteins will be, respectively, enriched and eliminated in nascent axons by differential proteasome degradation. In addition, proteasomal removal of axon-promoting proteins in nascent dendrites ensures formation of a single axon. For example, axon differentiation is initiated in part by phosphatidylinositol-3-kinase (PI3K) activation of Akt (Jiang et al., 2005), which is restricted to the future axon as a result of its proteasomal degradation in the prospective dendritic branches (Yan et al., 2006). In concert with PI3K, localized axonal accumulation of portioning-defective proteins (Par) contributes to axonal specification (Shi et al., 2003). Interestingly, the E3 ligase Smurfl can induce degradation of either portioning-defective protein 6 (Par6) and the growth-disrupting small GTPase RhoA 
depending on its phosphorylation status (Cheng et al., 2011a). Specifically, BDNF, identified as a symmetry-breaking cue (Cheng et al., 2011b; Nakamuta et al., 2011), stimulates Smurf1 phosphorylation, which then loses affinity for Par6 and preferentially ubiquitinates RhoA. This increases the spatial gradient of Par6 versus RhoA, which is required for axon formation (Cheng et al., 2011a). Smurf1 is itself sent for degradation by the E3 complex Cdh1APC, which ultimately controls axon growth (Kannan et al., 2012). The spatiotemporal enrichment of axonal-promoting proteins at unspecified neurites, created by differential local proteolysis (Fig. 2A), is further reinforced by axonal degradation of the RhoA activator Rho guanine nucleotide exchange factor by the KLHL20-based E3 ligase complex (Lin et al., 2011) and by the joint action of another proteolytic system, the calpains [beyond the scope of this review but nicely reviewed elsewhere (Bórquez and González-Billault, 2011)]. Despite the plausibility of this UPSfacilitated asymmetry model, differences in the behavior of nascent axons in culture and in intact tissue indicate that in vivo validation of UPS involvement should be sought.

\section{Axon outgrowth}

After a neurite has been specified as the axon, it must grow until it reaches its target. Axon outgrowth is primarily driven by dynamic cytoskeleton rearrangements that propel the axon forward, bolstered by changes in gene expression that favor growth (Polleux and Snider, 2010). Accumulating evidence suggests that the UPS modulates axon growth by acting at both of these levels (Fig. 2B,C; Table 1), as discussed below.

In the nucleus, the E3 complex Cdh1-APC acts as a negative regulator of genes involved in axon growth and patterning (Fig. 2B) (Yang et al., 2010). Indeed, mice lacking Cdh1 have longer axons (Konishi et al., 2004). Activation of Cdh1-APC in the nucleus enhances ubiquitination and proteasomal degradation of the transcriptional regulators SnoN (Stegmüller et al., 2006) and inhibitor of DNA binding 2 (Id2) (Lasorella et al., 2006). Whereas SnoN upregulates the expression of axonally enriched growth-promoting proteins (e.g., the scaffold protein Cdcl) (Ikeuchi et al., 2009), Id2 leads to downregulation of growth-inhibiting proteins (e. g., the Nogo receptor) (Lasorella et al., 2006). By inducing degradation of SnoN and Id2, Cdh1-APC leads to inhibition of positive axon growth modulators and disinhibition of negative growth modulators, thus repressing axonal growth. Interestingly, Akt phosphorylation of $\mathrm{Id} 2$ prevents its association with Cdh1-APC, thereby preventing proteasomal degradation and enhancing Id 2 protein stability. Subsequently, Id 2 is translocated to the growth cone, where it contributes to growth cone formation and axon outgrowth via interaction with radixin, a protein known to regulate growth cone dynamics by linking F-actin to the plasma membrane (Ko et al., 2016). How activity of nuclear Cdh1-APC is adjusted to fit the growing needs of a developing or regenerating axon remains elusive. Given that axonal growth is generally triggered by external cues, a yet unknown retrograde signal is likely to be involved.

Outside the nucleus, the UPS regulates axon growth by locally interfering with the cytoskeleton elements engaged in motion, such as actin microfilaments in the growth cone and tubulin microtubules along the axon shaft (Fig. 2C). LIM kinase 1 enhances polymerization of $\mathrm{F}$-actin and thus accelerates axon extension (Rosso et al., 2004). Its levels in the growth cone are negatively regulated by the E3 ligase RING finger protein 6, which thus shortens axons (Tursun et al., 2005). In addition, the axonal actin cytoskeleton is indirectly regulated by the UPS through the control of phosphatase and tensin homolog (PTEN) levels, a negative regulator of PI3K control of cytoskeleton dynamics (Jiménez et al., 2000). Both in rat and Xenopus, PTEN is targeted for proteasome degradation by the E3 ligase Nedd4, and this enhances axons' capacity to grow and branch (Christie et al., 2012). Together, these studies reveal that the UPS controls actin dynamics by modulating the levels of actin cytoskeleton regulators. Nevertheless, the highly dynamic behavior of actin filaments would benefit from a faster mode of regulation, which ubiquitin could potentially offer by affecting the activity and interaction properties of actin regulators directly, rather than by targeting proteins for degradation. Identification of such modulation awaits future study.

Ubiquitin has also been shown to limit axon growth by interfering with remodeling of microtubules, dynamic cytoskeletal elements that are essential for axon extension and stabilization. For instance, levels of katanin-p60, a subunit of a microtubuledisassembling enzyme (McNally and Vale, 1993), are balanced by the concerted action of the E3 ligase C-terminus of Hsp70interacting protein and the deubiquitinase ubiquitin-specific protease (USP) 47 (Yang et al., 2013). In a context favoring stability of katanin-p60, such as FGF-induced USP47 upregulation, microtubules dynamics are sustained, thus promoting axon growth (Yang et al., 2013).

In addition, modulation of microtubule dynamics by E3 ligases is likely to occur through effects on $\mathrm{Wnt} / \beta$-catenin signaling. This signaling pathway alters microtubule organization (Hall et al., 2000; Packard et al., 2002) and maintains the balance between axonal outgrowth and growth cone enlargement by regulating microtubule dynamics (Purro et al., 2008). In Caenorhabditis elegans and Drosophila, PLR-1 and HUWE1 are E3 ligases that help regulate axon outgrowth and branching (Vandewalle et al., 2013; Bhat et al., 2015), likely by adjusting the availability of components of the $\mathrm{Wnt} / \beta$-catenin pathway (Vandewalle et al., 2013; Moffat et al., 2014; Bhat et al., 2015), such as disheveled (Vandewalle et al., 2013), which is required for Wnt-mediated microtubule reorganization and hence changes in axon behavior (Krylova et al., 2000; Ciani et al., 2004; Purro et al., 2008). Notably, other components of Wnt signaling (Table 2) are liable to undergo ubiquitin regulation, and therefore are also potentially involved in ubiquitin-dependent modulation of microtubule dynamics. Another E3 likely involved is the E3 ligase protein family PHR (human PAM or Mycbp2, mouse Phr1 or Mycbp2, zebrafish Esrom, Drosophila Highwire and C. elegans RPM-1), which has roles in both axon and synapse development (for a comprehensive review, see Po et al., 2010). Deletion of PHR has deleterious effects on axon navigation, with axons failing to reach their correct destination (Bloom et al., 2007; Lewcock et al., 2007; Hendricks and Jesuthasan, 2009). The authors concluded that these phenotypes resulted from aberrant microtubule dynamics that could be corrected by pharmacological manipulation of microtubule assembly (Lewcock et al., 2007; Hendricks and Jesuthasan, 2009). Interestingly, growth cones from phr mutant axons (Lewcock et al., 2007; Hendricks and Jesuthasan, 2009) are strikingly similar to those obtained after Wnt stimulation or dishevelled overexpression (Purro et al., 2008), thus suggesting the likely involvement of $\mathrm{Wnt} / \beta$-catenin signaling in PHR-mediated axon outgrowth via modulation of microtubule dynamics. It is, however, imperative to validate this correlation in future investigations and precisely define how axon-enriched E3 ligases locally control canonical and atypical Wnt/ $\beta$-catenin pathways. Nevertheless, these studies highlight the role of UPS in modulating axon development primarily through dynamic changes in microtubule organization. 
Table 1. Ubiquitination machinery and targeted axonal substrates working locally to regulate axon development and function ${ }^{a}$

\begin{tabular}{|c|c|c|c|c|c|c|c|}
\hline E3 & Axonal target & Ub chain & Outcome of ubiquitination & Neuronal compartment & Role in axon & Model & Reference \\
\hline & $\mathrm{AKT}^{b}$ & polyUb & Prot deg & dendrites & Axon specification & Rat & Yan et al., 2006 \\
\hline KLHL2O & RhoGEF & polyUb & Prot deg; RhoA inactivation & axon & & Rat & Lin et al., 2011 \\
\hline \multirow[t]{2}{*}{ Smurf1 } & Par6 & polyUb & Prot deg & axon & & Rat & Cheng et al., 2011a; Deglincerti et al., 2015 \\
\hline & RhoA & polyUb & & & Axon specification/growth cone collapse & & \\
\hline Praja2 & Nogo-A & polyUb & Prot deg & axon & Axon outgrowth & Rat; mouse & Sepe et al., 2014 \\
\hline RNF6 & LIMK1 & - & Prot deg; reduced actin dynamics & growth cone & Inhibition of axon outgrowth & Mouse & Tursun et al., 2005 \\
\hline CHIP & katanin-p60 & polyUb & Prot deg; altered microtubule dynamics & axon & Inhibition of axon outgrowth & Rat & Yang et al., 2013 \\
\hline PLR-1 & - & - & Disruption of Wnt $/ \beta$-catenin pathway & axon & Axon outgrowth/axon guidance & C.el & Bhat et al., 2015 \\
\hline \multirow[t]{3}{*}{ HUWE1 } & dishevelled & - & & axon & Axon branching & Dro & Vandewalle et al., 2013 \\
\hline & - & - & - & presynaptic terminal & GABAergic transmission & C.el & Opperman et al., 2017 \\
\hline & MBNL1 & K63 & Cytoplasmic localization & axon & Axon outgrowth & Mouse & Wang et al., 2018 \\
\hline EBAX-CRL & Roundabout & - & Degradation of misfolded protein & axon & Accuracy of guidance signaling & Dro & Wang et al., 2013 \\
\hline TRIM9 & VASP & - & Growth cone localization & growth cone & Axon guidance & Mouse & Menon et al., 2015 \\
\hline \multirow[t]{2}{*}{ Nedd4 } & PTEN & - & Prot deg & growth cone & Axon branching/axon outgrowth & Xen; Rat & Drinjakovic et al., 2010; Christie et al., 2012 \\
\hline & Commissureless & monoUb & Endocytosis & growth cone; muscle & Axon guidance/synaptic formation & Dro & Myat et al., 2002; Ing et al., 2007 \\
\hline \multirow[t]{4}{*}{ Cdh1-APC } & Smurf1 & polyUb & Prot deg & axon & Inhibition of axonal outgrowth & Rat & Kannan et al., 2012 \\
\hline & SnoN & polyUb & Prot deg & nucleus & & Rat & Stegmüller et al., 2006 \\
\hline & Id2 & polyUb & Prot deg & nucleus & & Rat & Lasorella et al., 2006 \\
\hline & Liprin $\alpha$ & - & - & presynaptic terminal & Synaptic size/GABAergic transmission & Dro; C.el & van Roessel et al., 2004; Kowalski et al., 2014 \\
\hline CdC20-APC & NEUROD2 & polyUb & Prot deg & nucleus & Promotion of presynaptic differentiation & Rat & Yang et al., 2009 \\
\hline UBEЗ & thickveins & K48 & Prot deg & presynaptic terminal & Suppression of presynaptic formation & Dro & Li et al., 2016 \\
\hline RNF8 & - & - & - & axon & Suppression of presynaptic formation & Mouse & Valnegri et al., 2017 \\
\hline \multirow[t]{6}{*}{$\mathrm{PHR}^{c}$} & - & - & Altered microtubule dynamics & axon & Axon outgrowth/pathfinding & Zeb; mouse & $\begin{array}{l}\text { Bloom et al., 2007; Lewcock et al., 2007; } \\
\text { Hendricks and Jesuthasan, } 2009\end{array}$ \\
\hline & ALK & - & Prot deg? & presynaptic terminal & Presynaptic formation & C.el & Liao et al., 2004 \\
\hline & DLK & polyUb & Prot deg? & presynaptic terminal & Presynaptic formation & C.el & Nakata et al., 2005; Collins et al., 2006; \\
\hline & & & & & & Dro & $\begin{array}{l}\text { Wu et al., 2007; Shin and DiAntonio, 2011; } \\
\text { Opperman and Grill, } 2014\end{array}$ \\
\hline & Munc13/Dunc13 & - & Prot deg & presynaptic terminal & Presynaptic release & Mouse; Dro & Speese et al., 2003; Tada et al., 2010 \\
\hline & NMNAT2 & polyUb & Prot deg & axon & Axon degeneration/presynaptic release & Dro; mouse & $\begin{array}{l}\text { Xiong et al., 2012; Yamagishi and Tessier-Lavigne, 2016; } \\
\text { Russo et al., } 2019\end{array}$ \\
\hline ZNRF1 & AKT & polyUb & Prot deg & axon & Axon degeneration & Mouse & Wakatsuki et al., 2011 \\
\hline FBXW7 & MCL1 & polyUb & Prot deg & axon & Axon degeneration & Mouse & Wakatsuki et al., 2017 \\
\hline $\mathrm{SCF}^{\mathrm{SEL}-10}$ & - & - & - & axon & Synapse elimination & C.el & Ding et al., 2007 \\
\hline SCF SCRAPEER & RIM1 & polyUb & Prot deg & presynaptic terminal & Presynaptic release & Mouse & Yao et al., 2007 \\
\hline RNF13 & snapin & $\mathrm{K} 29$ & Higher association with SNAP25 & presynaptic terminal & SNARE complex assembly & Mouse & Zhang et al., 2013 \\
\hline $\mathrm{SCF}^{\mathrm{MEC}-15}$ & VAMP & - & Synaptic abundance & axon & GABAergic transmission & C.el & Sun et al., 2013 \\
\hline E2 & \multicolumn{5}{|l|}{ Role in axon } & Model & Reference \\
\hline Bendless & \multicolumn{5}{|c|}{ Initial stages of presynaptic formation } & Dro & Uthaman et al., 2008 \\
\hline UEV-3 & \multicolumn{5}{|c|}{ Control of RPM-1/DLK-1 cascade in presynaptic formation } & C.el & Trujillo et al., 2010 \\
\hline $\mathrm{UBC} 13$ & \multicolumn{5}{|c|}{ Suppression of presynaptic formation } & Mouse & Valnegri et al., 2017 \\
\hline Deubiquitinase & Target & \multicolumn{4}{|c|}{ Role in axon } & Model & Reference \\
\hline USP47 & katanin-p60 & \multicolumn{4}{|c|}{ Axon outgrowth } & Rat & Yang et al., 2013 \\
\hline USP4/USP20 & - & \multicolumn{4}{|c|}{ Axon outgrowth } & Rat & Anckar and Bonni, 2015 \\
\hline USP33 & Roundabout & \multicolumn{4}{|c|}{ Axon guidance } & Mouse & Yuasa-Kawada et al., 2009 \\
\hline Fat facets & Liquid facets & \multicolumn{4}{|c|}{ Promotion of presynaptic formation } & Dro & DiAntonio et al., 2001; Bao et al., 2008 \\
\hline USP14 & - & \multicolumn{4}{|c|}{ Presynaptic formation and function } & Mouse & Chen et al., 2009; Bhattacharyya et al., 2012 \\
\hline
\end{tabular}

${ }^{a}$ ALK, Anaplastic lymphoma kinase; C.el, C. elegans; CHIP, C-terminus of Hsp70-interacting protein; Dro, Drosophila; EBAX-CRL, EBAX-type Cullin-RING; Id2, inhibitor of DNA binding 2; LIMK1, LIM kinase 1; monoUb, monoubiquitin; Par, portioning-defective proteins; polyUb, polyubiquitin; Prot deg, proteasomal degradation; RIM1, Rab3-interacting molecule 1; RhoGEF, Rho guanine nucleotide exchange factor; UBC13, ubiquitin-conjugating enzyme 13: VAMP, vesicle-associated membrane protein; Xen, Xenopus; Zeb, zebrafish; ZNRF1, zinc and ring finger 1.

${ }^{b}$ In HeLa cells, Akt was shown to be negatively regulated in a UPS manner by the E3 ligase mitochondrial ubiquitin ligase activator of NF- $\kappa$ B (MULAN) (Bae et al., 2012).

'PHR proteins form atypical cullin-free SCF complexes containing Skp and an F-box protein: FSN1-RPM1 (C.el) (Liao et al., 2004), DFsn-Highwire (Dro) (Brace et al., 2014), and Fbxo45-PAM (mouse) (Saiga et al., 2009).

Ubiquitination can also regulate axon elongation in a nonproteolytic manner by influencing the intracellular trafficking of growth regulators. This is the case of muscleblind-like protein 1 (MBNL1), an RNA metabolism regulator whose cytoplasmic localization in neurons is secured by its K63 polyubiquitination (Wang et al., 2018). While in the cytoplasm, MBNL1 promotes axonal outgrowth, but this effect halts when MBNL1 undergoes deubiquitination and subsequent nuclear translocation (Wang et al., 2018). Of note, several other proteins involved in axon formation are targets of ubiquitin modulation (Table 2), hinting at a much wider impact of axonal ubiquitination than currently appreciated. Of particular interest is the involvement of ubiquitin in controlling the surface levels of several members of the receptor tyrosine kinase family (e.g., FGF receptor, TrK, insulin-like growth factor receptor, and epidermal growth factor receptor), which are abundantly expressed at the axonal membrane and known to coordinate axon formation (Williams et al., 1994; Koprivica et al., 2005; Cheng et al., 2011b; Dupraz et al., 2013).

\section{Axon guidance}

Axon outgrowth per se would be pointless without mechanisms securing accurate navigation through the tissue, a process known 
Table 2. Additional axonal proteins whose ubiquitin regulation had hitherto not been implicated in axon development and function ${ }^{a}$

\begin{tabular}{|c|c|c|c|c|c|c|}
\hline Axonal protein & Known function in the axon & Axonal localization & E3 & Ub chain & Outcome of ubiquitination & Reference \\
\hline $\mathrm{K}_{\mathrm{v}} 7$ channels & Neuronal excitability & AIS & Nedd4 & polyub & Endocytosis & Jespersen et al., 2007 \\
\hline $\mathrm{FGFR}^{b}$ & Receptor tyrosine kinase signaling/axon formation & axon & & & Endocytosis; Lys deg & Haugsten et al., 2008; Persaud et al., 2011 \\
\hline $\mathrm{TrK}^{b}$ & and regeneration & axon & & multimonoub & Endocytosis; Lys deg & Arévalo et al., 2006; Georgieva et al., 2011; Murray et al., 2019 \\
\hline \multirow[t]{2}{*}{ IGF- $-1 R^{b}$} & & axon & & multimonoub & Endocytosis; Prot and Lys deg & Vecchione et al., 2003; Monami et al., 2008 \\
\hline & & & $\mathrm{Mdm} 2 / \mathrm{Cbl} \quad \mathrm{K} 63 / \mathrm{K} 48$ & Endocytosis & & Sehat et al., 2008 \\
\hline \multirow[t]{2}{*}{$\mathrm{EGFR}^{b}$} & & $>$ axon & $\mathrm{cbl}$ & multimonoub & Endocytosis; Lys deg & Haglund et al., 2003; Mosesson et al., 2003 \\
\hline & & & HUWE1 & polyUb & Prot deg & Zhu et al., 2020 \\
\hline $\tan ^{b}$ & Microtubule stabilization & axon & axotrophin & multimonoub & Reduced microtubule binding & Flach et al., 2014 \\
\hline Frizzled $^{b}$ & Wnt signaling component/axon and synapse formation & axon & RNF43 PLR-1 (C.el) & multimonoub & Endocytosis; Lys deg & Hao et al., 2012; Koo et al., 2012; Moffat et al., 2014 \\
\hline $\operatorname{axin}^{b}$ & Wnt signaling component/axon formation & axon growth cone & Smurf1 & K29 & No interaction with LRPG; Repression of Wnt/ $\beta$ cat & Fei et al., 2013 \\
\hline \multirow[t]{2}{*}{$\beta$-catenin ${ }^{b}$} & Wnt signaling component/axon formation/presynaptic & axon & EDD & $\mathrm{K} 11 / 29$ & Enhanced stability & Hay-Koren et al., 2011 \\
\hline & formation and release & & $\operatorname{Siah}^{e}$ & K11 & Prot deg & Dimitrova et al., 2010 \\
\hline DCC & Netrin receptor/axon guidance & axon growth cone & & polyUb & Prot deg & Hu et al., 1997; Kim et al., 2005 \\
\hline Synaptophysin ${ }^{c}$ & Synaptic vesicles protein/presynaptic release & presynaptic terminal & & polyub & Prot deg & Wheeler et al., 2002 \\
\hline Synphilin-1 $1^{c}$ & Synaptic vesicles protein & & & polyUb & Prot deg & Nagano et al., 2003; Liani et al., 2004 \\
\hline$\alpha$-synuclein ${ }^{c}$ & Synaptic vesicles clustering and exocytosis/endocytosis & & 2 & monoUb & Prot deg & Liani et al., 2004; Rott et al., 2011 \\
\hline $\mathrm{mGlu} 7^{c}$ & Presynaptic release & & Nedd4 & K48/63 & Endocytosis; Prot and Lys deg & Lee et al., 2019 \\
\hline Syntaxin $^{c}$ & SNARE complex component/presynaptic release & & Staring & polyUb & Prot deg & Chin et al., 2002 \\
\hline Synaptotagmin ${ }^{c}$ & Calcium sensor/presynaptic release & & Parkin & polyUb & Prot deg & Kabayama et al., 2017 \\
\hline CDCrel-1 $1^{c}$ & Synaptic vesicles GTPase/presynaptic release & & & polyUb & Prot deg & Zhang et al., 2000 \\
\hline Eps15 $15^{c}$ & Endocytic adaptor protein/synaptic vesicles endocytosis & & & monoUb & No interaction with partners (e.g., EGFR) & Fallon et al., 2006 \\
\hline $\mathrm{Ca}_{\mathrm{v}} 2.2^{\mathrm{c}}$ & Presynaptic release & & - & polyUb & Prot deg & Marangoudakis et al., 2012; Ferron et al., 2014 \\
\hline CASK $^{c}$ & Active zone scaffolding protein & & - & polyUb & Prot deg & Sun and Kelly, 2010 \\
\hline Bruchpilot ${ }^{c}$ & & & - & polyUb & Prot deg & Zang et al., 2013 \\
\hline Syntenin $^{c}$ & & & - & polyub & & Okumura et al., 2011 \\
\hline \multicolumn{7}{|c|}{ Additional axonal proteins candidates for ubiquitin regulation } \\
\hline \multirow{2}{*}{\multicolumn{2}{|c|}{ Identified in Drosophila embryos ubiquitome }} & \multirow{2}{*}{\multicolumn{4}{|c|}{$\begin{array}{l}\text { Fax, Akap200, Hsp83, Hsp26, Eps15, flotillin1/2, 14-3-3, fasciclin 2/3 } \\
\text { Hsc70-4, neurotactin, TER94, Hsp27, ArgK, Enolase }\end{array}$}} & Franco et al., 2011 \\
\hline & & & & & & \\
\hline \multicolumn{2}{|c|}{ Identified in the rat brain ubiquitome } & \multicolumn{4}{|c|}{ Bassoon, NSF, SNAP25, synapsin, SV2, VGluT, APP, neurexin ${ }^{c}$} & Na et al., 2012 \\
\hline \multicolumn{2}{|c|}{ Identified in mouse APP pulldown ubiquitome } & \multicolumn{4}{|c|}{ Scamp1, SV2, VAMP2, VGluT, SNAP25, synapsinc } & Del Prete et al., 2016 \\
\hline \multicolumn{2}{|c|}{ Proteasome-dependent expression in rat } & \multicolumn{4}{|c|}{ Bassoon, liprin- $\alpha$, synapsin, syntaxin, CAST/ELKS, $\alpha / \beta$-SNAP, SNAP25, neurexin ${ }^{c}$} & Lazarevic et al., 2011; Hakim et al., 2016 \\
\hline
\end{tabular}

${ }^{a}$ AIS, Axon initial segment; APP, amyloid precursor protein; ArgK, arginine kinase; CASK, calcium/calmodulin-dependent serine kinase; CAST/ELKS, CAZ-associated structural protein/ELKS; DCC, deleted in colorectal cancer; EDD, E3 ubiquitin ligase identified by differential display; EGFR, epidermal growth factor receptor; Eps15, endocytic adaptor epidermal growth factor receptor substrate 15; Fax, failed axon connection; FGFR1, FGF receptor 1; Hsp, heat-shock protein; Lys deg, lysosomal degradation; mGlu7, metabotropic glutamate receptor 7; multimonoUb, multi-monoubiquitin; NSF, ATPase N-ethylmaleimide-sensitive fusion protein; polyUb, polyubiquitin; Prot deg, proteasomal degradation; RNF, RING finger protein; SNAP25, synaptosomal-associated protein 25; SV2, synaptic vesicle glycoprotein 2; VAMP, vesicle-associated membrane protein; VGluT, vesicular glutamate transporter.

${ }^{b}$ Protein with known role in axon formation.

'Protein with known role in presynaptic release.

dProtein with known role in synaptogenesis.

eSiah activity was proposed to be regulated by Bassoon and Piccolo (Waites et al., 2013).

as axon guidance. The directed growth of axons in the complex embryonic environment relies on the ability of axonal growth cones to respond to multiple sources of spatial information in the form of guidance cues. This is achieved through the spatiotemporally regulated expression of specific receptors that integrate information from various guidance cues to steer the axon in the right direction. The dynamic changes in growth cone behavior rely on many cellular mechanisms, including transcription, local translation, protein trafficking, and post-translational processing of guidance receptors (Stoeckli, 2018). In addition, ubiquitin signaling is actively involved, as highlighted by the severe defects in axon pathfinding observed on deletion of E3 ligases. PHR loss leads to impaired segregation of axons to different lobes in Drosophila (Shin and DiAntonio, 2011); and in mice, it leads to loss of retinal innervation and sensory innervation of the dorsal olfactory bulb (Bloom et al., 2007; James et al., 2014). Moreover, downregulation of Nedd4 suppresses midline crossing by commissural axons (Myat et al., 2002); and mice lacking TRIM9, a member of the tripartite motif (TRIM) family of E3 ligases, show defects in cortical projections (Menon et al., 2015).

Mechanistically, ubiquitin control of axon guidance occurs at the growth cone level. Early findings suggested that guidance cues steer axons by triggering rapid local changes in growth cone protein content, in part through ubiquitination and proteasome activity (Campbell and Holt, 2001). Although the full impact of such local activation of ubiquitination and proteolytic pathways remains elusive, evidence supports cue-mediated control of axonal responsiveness by altered expression of guidance receptors (Fig. 2D; Table 1). Indeed, levels of the netrin receptor deleted in colorectal cancer are decreased by netrin itself through the UPS (Kim et al., 2005).

A prime example of ubiquitin-mediated control of guidance receptors occurs as commissural axons cross the midline. During this time, axons' responsiveness to the midline repulsive cue Slit is kept low by preventing membrane localization of the Slit receptor Roundabout (Kidd et al., 1998, 1999). In flies, the mechanism goes as follows: the transmembrane protein Commissureless is a Roundabout binding partner whose surface levels are downregulated by Nedd4-mediated ubiquitination and internalization into late endosomes. Roundabout is internalized together with Commissureless, thus keeping minimal levels of the receptor at the axonal surface (Myat et al., 2002). After the growth cone has crossed the midline, Commissureless/ Roundabout internalization is halted, leading to increased surface levels of Roundabout and gained sensitivity to Slit; this prevents midline recrossing, thus ensuring accurate pathfinding (Myat et al., 2002). In mammals, the Nedd4-family interacting proteins Ndfip1 and Ndfip2 function analogously to Commissureless in 
removing Roundabout from the axonal membrane through ubiquitin-dependent degradation (Gorla et al., 2019). Downregulation of Roundabout is counteracted by the deubiquitinase USP33, which interacts with Roundabout and favors its stability in a Slit1enriched environment (Yuasa-Kawada et al., 2009).

The UPS also maintains accuracy of axon guidance by performing protein quality control and degrading misfolded Roundabout proteins (Wang et al., 2013). Briefly, the EBAX-type Cullin-RING E3 ligase interacts with the cytosolic chaperone heat shock protein 90 and can regulate axon guidance by tagging for proteasome degradation damaged Roundabout receptors that accumulate in newborn C. elegans grown in higher temperature conditions (Wang et al., 2013). Whether similar quality control mechanisms are present in more complex organisms awaits future studies.

In addition, ubiquitination may regulate axonal responses to guidance cues by locally interfering with cytoskeletal regulatory proteins. VASP is an actin polymerase that is present at filopodia tips and is required for netrin-1-dependent increases in growth cone filopodia number (Lebrand et al., 2004). VASP is ubiquitinated by the E3 TRIM9, which directly binds to the netrin receptor deleted in colorectal cancer. Once ubiquitinated, VASP localization and actin polymerization at filopodia tips are markedly reduced, causing filopodial instability (Menon et al., 2015). Netrin induces VASP deubiquitination by a yet unknown deubiquitinase that counteracts TRIM9 action and thus allows the axon to move toward netrin. Accordingly, TRIM9 deletion causes axon guidance defects by disrupting the attractive turning of cortical axons toward netrin both in vitro and in vivo (Menon et al., 2015).

Overall, ubiquitin signaling seems to contribute to the maintenance of axon pathfinding by tuning the surface levels of guidance cue receptors and actin regulators (Fig. 2D). The literature suggests that this level of control is geared by guidance cues, raising the exciting questions of whether and how extrinsic factors engage the axonal ubiquitination cascade and/or the proteasome. Chances are that signaling initiated by guidance receptors controls the activity of both E3 ligases and deubiquitinases, which might be anchored to the receptor. Such localization would create rapidly activatable (de)ubiquitination hubs in the steering growth cone, and these in turn could control downstream effectors. Future investigation will certainly shed light on the axon intrinsic pathways translating extrinsic signals into appropriate axonal behavior through modification of ubiquitination.

\section{Presynapse formation}

After reaching its target, the axon undergoes a series of modifications to give rise to presynaptic terminals juxtaposed to postsynaptic specializations. In broad terms, presynaptic material will be recruited to specified axonal sites and properly assembled into an active zone near which synaptic vesicles are packed (Pinto and Almeida, 2016).

Throughout development, the amount of ubiquitin-related machinery and ubiquitinated conjugates fluctuates throughout development with a peak coincident with synaptogenesis (Petersen et al., 2010; Chen et al., 2011; Franco et al., 2011), suggesting that ubiquitination cascades are highly industrious and dynamic at this stage. Indeed, in Drosophila embryos, several proteins with known roles in synaptogenesis are substrates for ubiquitination, including structural and signaling proteins, such as adhesion molecules, presynaptic scaffolds, kinases, and chaperones (Franco et al., 2011) (Table 2). We and others observed enhancement of presynaptic formation on proteasome inhibition (Zhao et al., 2003; Pinto et al., 2016a), suggesting that modulation of axonal proteasome activity may provide spatiotemporal control of synaptogenesis onset. We further concluded that, downstream of local UPS inhibition, on-site accumulation of proteins in a K11 and K48 polyubiquitinated state functions as a triggering signal for presynaptic clustering (Pinto et al., 2016a,b). This suggests that the ubiquitinated state of axonal proteins modulates presynaptic assembly. In agreement with this concept, downregulation of the deubiquitinases USP14 and Ubiquitin Cterminal hydrolase L1 (UCH-L1) leads to severe synaptic malformations as the result of a reduction in the synaptic ubiquitin pool and therefore in the ubiquitination competence of these synaptic terminals (Osaka et al., 2003; Cartier et al., 2009; Chen et al., 2009, 2011). Furthermore, in the Drosophila neuromuscular junction (NMJ), overexpression of the deubiquitinase Fat facets and loss-of-function mutations in Highwire, the PHR Drosophila homolog, both result in synaptic overgrowth (Wan et al., 2000; DiAntonio et al., 2001). The PHR loss-of-function phenotype is suppressed in the absence of Fat facets (DiAntonio et al., 2001), further indicating that dynamic (de)ubiquitination-dependent mechanisms act to regulate presynaptic differentiation. Future work will certainly help to fully characterize the molecular basis of such ubiquitin-dependent control, including the axonal regulators of ubiquitination, topology of chains and involved substrates, recognition and decoding machinery, and downstream cascades leading to presynaptic formation.

Modulation of presynapse assembly by ubiquitin occurs, at least partially, by controlling levels of specific proteins. Pioneer efforts to identify targets of ubiquitin modifications revealed that PHR, which forms a noncanonical SCF complex with Skp (Brace et al., 2014) and the F-box protein DFsn (Wu et al., 2007), downregulates Wallenda, the Drosophila homolog of dual leucine-zipper-bearing kinase (DLK) (Collins et al., 2006; Wu et al., 2007). This kinase activates a signaling pathway involving c-Jun N-terminal kinase activity and Fos-mediated transcription that confers synaptogenic capacity. Therefore, PHR restrains synaptic development by promoting DLK elimination (Collins et al., 2006). Synaptic overgrowth induced by the deubiquitinase Fat facets also converges on DLK (Collins et al., 2006), emphasizing that, in Drosophila, DLK is a key substrate whose ubiquitinated status determines the propensity to form presynaptic specializations. In addition, Fat facets acts via the epsin 1 Drosophila homolog Liquid facets, a protein involved in endocytosis (Bao et al., 2008). Together, these studies laid the groundwork for the identification of the molecular mechanisms underlying ubiquitin-driven control of presynaptic formation through its action at nascent terminals (Fig. 3A; Table 1).

Notably, the involvement of PHR in presynaptic formation is conserved between species. In C. elegans, the PHR protein RPM1 , rather than restricting presynaptic development, promotes it by negatively targeting DLK, which initiates a cell-autonomous kinase cascade that suppresses presynaptic development (Nakata et al., 2005). RPM-1 further controls the extent and positioning of presynaptic formation by locally modulating levels of anaplastic lymphoma kinase. This is accomplished by an SCF-like complex comprising the F-box protein FSN-1 and RPM-1 in the periactive zone (Liao et al., 2004). Of note, the fact that the F-box protein Fbxo45 (human ortholog of C. elegans FSN-1 and Drosophila DFsn) associates with PAM (human PHR homolog) and that mice lacking both Phr1 and Fbxo45 display severe synaptic defects (Burgess et al., 2004; Saiga et al., 2009) makes it likely that similar modes of regulation underlie synapse formation in mammals. 

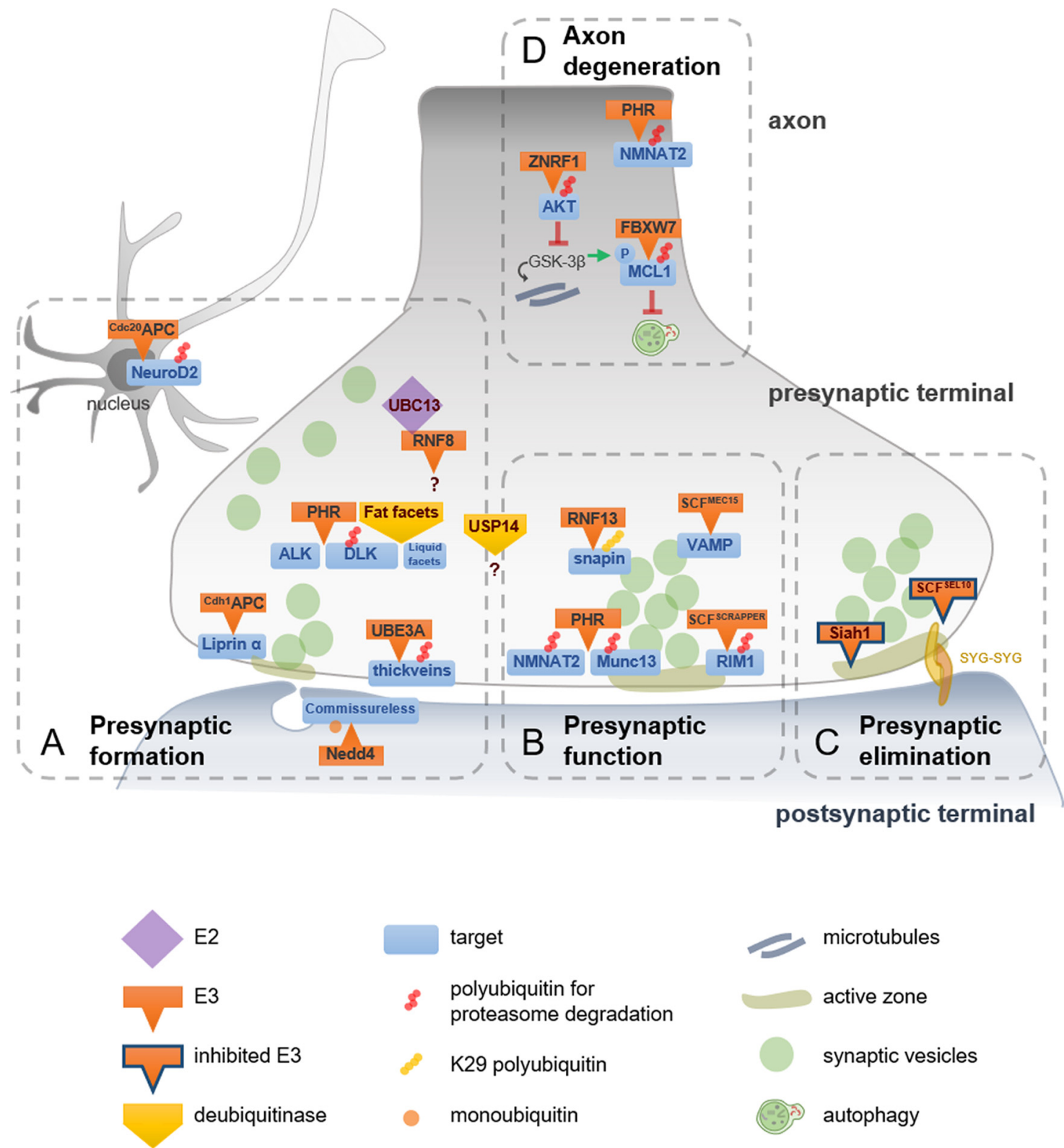

target
polyubiquitin for
proteasome degradation
K29 polyubiquitin
monoubiquitin

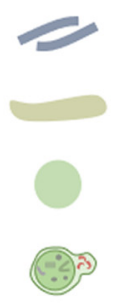

microtubules

active zone

synaptic vesicles

autophagy

Figure 3. Ubiquitin-dependent signaling in the lifetime of presynaptic terminals. Following correct pathfinding, an axon establishes synaptic contacts ( $\boldsymbol{A}$, presynaptic formation), which mature into release-competent synaptic terminals ( $\boldsymbol{B}$, presynaptic function). Trimming of the axonal arbor ( $\boldsymbol{C}$, presynaptic elimination; and $\boldsymbol{D}$, axon degeneration) can occur during development or adulthood. All these axonal events are locally controlled by ubiquitin and/or the proteasome. Ubiquitin-targeted proteins (blue) and respective E3 ubiquitin ligases (orange) or deubiquitinases (yellow) are illustrated at their site of action. The type of ubiquitin chains involved is indicated. For complementary information, see Table 1. ALK, Anaplastic lymphoma kinase; RIM1, Rab3-interacting molecule 1; UBC13, ubiquitin-conjugating enzyme 13; VAMP, vesicle-associated membrane protein; ZNRF1, zinc and ring finger 1.

Additional axonal E3 ligases have emerged as important local players in orchestrating presynaptic formation (Fig. $3 A$ ). Presynaptically located Cdh1-APC downregulates the active zone scaffolding protein liprin- $\alpha$, thereby restricting presynaptic size (van Roessel et al., 2004). The E3 UBE3A mediates UPS degradation of the presynaptic bone morphogenetic protein receptor thickveins, a function that is conserved in mammalian cells (Li et al., 2016). Loss of UBE3A increases the density of synaptic boutons at the Drosophila NMJ through excessive activation of signaling by bone morphogenetic protein (Li et al., 2016), a secreted polypeptide that retrogradely promotes NMJ growth through activation of thickveins (Aberle et al., 2002; McCabe et al., 2003).

Recently, a novel cytoplasmatic ubiquitin cascade comprising the E2 ubiquitin-conjugating enzyme 13 and the E3 RNF8 was identified in the mouse cerebellum and was shown to suppress synapse formation between granule cells and Purkinje neurons (Valnegri et al., 2017). Efforts to identify the involved players downstream this ubiquitination cascade are expected to offer insights into the ubiquitin-related local pathways in vertebrates, which have so far evaded us. Caution should be exercised in the interpretation and generalization of future work, however, because synapse type- or region-specific modulations are highly likely.

Interestingly, ubiquitin-mediated protein removal controls synapse formation by acting not only at the site of nascent terminals but also at other locations (Fig. 3A). In the nucleus, the E3 complex Cdc20-APC ubiquitinates and sends for proteolysis the transcription factor NeuroD2 (Yang et al., 2009), thus precluding expression of complexin, a protein that normally acts in the axon to obstruct formation of presynaptic sites. Accordingly, Cdc20-APC upre- 
gulation during synaptogenesis alleviates complexin-mediated constraint of presynaptic formation (Yang et al., 2009). Furthermore, in the postsynaptic muscle cell, ubiquitin can trigger presynapse formation by promoting endocytosis of the transmembrane protein Commissureless (Wolf et al., 1998; Ing et al., 2007). During the period of motoneuron-muscle interaction, Commissureless is highly expressed in the muscle cell, and its endocytosis is mandatory for synaptogenesis to be initiated (Wolf et al., 1998). This is promoted by monoubiquitinationinduced Commissureless internalization via the E3 Nedd4 located in the muscle cell (Ing et al., 2007). Thus, in Nedd4 mutant mice, axons project to the muscle but are unable to establish synaptic contacts (Y. Liu et al., 2009).

From the examples above, it appears that, by controlling the levels of specific targets, ubiquitin modulates presynaptic formation through three main routes: changes in gene expression, synapse-promoting kinase cascades, and synaptic scaffolds. The timing and sequence of this control are unclear. It is however tempting to speculate that ubiquitin-induced changes in transcription contribute to the priming of a developing neuron into a synaptogenic state, likely followed by ubiquitin local control of signaling pathways that launch the recruitment of synaptic material and scaffolds. Finally, analogous to the engagement of ubiquitin control by guidance cues, presynaptogenic cues (Pinto and Almeida, 2016) are potential upstream triggers, a link that is yet to be established.

\section{Presynaptic function}

The prime function of a fully formed presynaptic terminal is the release of neurotransmitters in a controlled and accurate manner following depolarization-induced presynaptic calcium entry (Südhof, 2013). Can ubiquitin regulate presynaptic release? Two main findings support a strong link between presynaptic release and ubiquitination. First, brief proteasome inhibition boosts neurotransmitter release without changing presynaptic protein levels (Speese et al., 2003; Zhao et al., 2003; Rinetti and Schweizer, 2010). Second, depolarization-induced calcium elevation rapidly decreases the presynaptic pool of ubiquitinated protein in a nonproteolytic manner (Chen et al., 2003). Together, these observations suggest that dynamic ubiquitination, not necessarily associated with proteasome clearance, controls the events surrounding neurotransmitter release. As a proof of concept, mice harboring a loss-of-function mutation in the deubiquitinase USP14, with concomitant loss of free ubiquitin and presynaptic ubiquitination (Chen et al., 2009, 2011), show an inability to mobilize synaptic vesicles for fusion and thus have reduced quantal release (Bhattacharyya et al., 2012). Such deficits are rescued on restoration of ubiquitin levels (Chen et al., 2009, 2011), further suggesting that presynaptic function is governed by a subset of dynamically ubiquitinated proteins. One notable example of the requirement of dynamic ubiquitination to presynaptic release involves the E3 RNF13 that adds a K29 ubiquitin chain to snapin, thus fortifying its association with the SNARE protein SNAP25 (Zhang et al., 2013). Snapin binding to SNAP25 potentiates SNAP25's interaction with synaptotagmin (Ilardi et al., 1999), thus accelerating the zippering of the SNARE complex that mediates synaptic vesicle fusion. This example emphasizes the ability of ubiquitin to rapidly convert inactive presynaptic proteins into active release machinery. Many other proteins involved in presynaptic release, including synaptic vesicle machinery and active zone scaffolds, are substrates of ubiquitinmediated regulation (Table 2). Moreover, if one considers the reversibility and versatility nature of ubiquitin signaling, it is quite expectable that additional modes of local nonproteolytic ubiquitin modulation control presynaptic release efficacy. We therefore believe that a thorough analysis of the presynaptic ubiquitome, including identification of substrates, analysis of chain topologies, and depolarization- or calcium-induced ubiquitination dynamics, would allow for great advances in the field. Moreover, the attractive possibility of a calcium-sensitive modulation of E3s and deubiquitinases' activity (Wang et al., 2010; Shimamoto et al., 2013), which could regulate ubiquitination in the range of seconds, should be explored at the presynaptic terminal.

Ubiquitin also regulates presynaptic function by controlling levels of active zone and synaptic vesicle proteins (Fig. 3B; Table 1). To maintain synaptic activity within reasonable levels and thus avoiding excessive release, activity of the E3 ligases SCRAPPER and the Fbxo45-containing PHR complex (Saiga et al., 2009) reduces levels of the active zone proteins Rab3-interacting molecule 1 and Munc13 (Yao et al., 2007; Tada et al., 2010), which function as coordinators of synaptic vesicle fusion. Accordingly, facilitation of excitatory transmission is observed on loss of SCRAPPER or Fbxo45 (Tada et al., 2010; Koga et al., 2017). In contrast, in Drosophila the E3 PHR maintains evoked release by attenuating levels of presynaptic nicotinamide mononucleotide adenylytransferase 2 (NMNAT2), a chaperone of active zone scaffolds which in excess dampens transmission by disturbing active zone structure (Russo et al., 2019).

E3s may also function in a synapse-type-specific manner to regulate the excitation/inhibition balance. In C. elegans, the Fbox protein MEC-15 maintains levels of the presynaptic protein synaptobrevin (homolog of mammalian vesicle-associated membrane protein) at GABAergic terminals and, accordingly, its loss impairs inhibitory transmission (Sun et al., 2013). Moreover, despite broad expression of the ubiquitin ligases HUWE1 and APC in C. elegans motor system, these proteins specifically affect presynaptic release of GABAergic inputs (Kowalski et al., 2014; Opperman et al., 2017). Further investigating the synapse specificity underlying E3-mediated presynaptic control in vertebrates may prove useful for the understanding of neurologic conditions involving altered excitation to inhibition ratio stemming from mutations in E3 ligases (Rotaru et al., 2018).

\section{Axonal self-destructive events}

Throughout the lifetime of an axon, there are occasions in which reorganization of the axonal arbor involving selective selfdestruction of axonal domains is necessary. Elimination of presynaptic terminals (Fig. 3C) and degeneration of axon segments (Fig. $3 D$ ) are examples of such self-destructive events in which, once more, the involvement of ubiquitin signaling is coming to light.

Following the initial boost in synapse formation, elimination of unwanted or unnecessary terminals refines the neuronal network. In C. elegans, elimination of extra presynaptic clusters in the hermaphrodite-specific motor neuron is mediated by an SCF complex (Ding et al., 2007). Terminals stabilized by the establishment of the SYG-SYG transsynaptic pair will be spared because of SYG-dependent inhibition of SCF assembly (Ding et al., 2007). Moreover, the active zone proteins Bassoon and Piccolo have been identified as important players in the maintenance of presynaptic integrity by regulating ubiquitination and degradation of presynaptic proteins. Through their zinc finger domains, Bassoon and Piccolo bind to and inhibit the E3 ligase Siah1. Their loss results in aberrant degradation of multiple presynaptic proteins, resulting in synapse elimination (Waites et al., 2013). These studies show that ubiquitination machinery can be 
anchored to and negatively regulated by presynaptic elements, thus preventing widescale degradation of presynaptic proteins that might ultimately result in synaptic degeneration. This implies that well-established, mature synapses exert a stronger restraining effect on these specific E3 ligases than weak or immature synapses, which are more vulnerable to elimination. Hence, local control of UPS degradation is likely to contribute to the selectivity of synaptic elimination and therefore refinement of neuronal networks during development. Whether neuronal activity governs UPS-based synaptic elimination and how it is coordinated with other ongoing cellular events are unresolved issues that would be important to address.

Axon degeneration occurs not only during development to refine the axonal tree, but also in pathologic contexts, such as after injury and in neurologic disorders. A classical model of axon degeneration is Wallerian degeneration, in which the distal portion of a severed axon undergoes fragmentation and elimination in an active cellular process triggered by depletion of nicotinamide adenine dinucleotide $\left(\mathrm{NAD}^{+}\right)$and activation of a kinase signaling cascade (Geden and Deshmukh, 2016). The broad-spectrum E3 PHR controls Wallerian degeneration in part through downregulation of the $\mathrm{NAD}^{+}$synthesizing and axon survival molecule NMNAT2 (Xiong et al., 2012). Consistent with this, depletion of PHR components increases axonal NMNAT2, thereby delaying axon degeneration after injury both in vitro and in vivo (Yamagishi and TessierLavigne, 2016). Likewise, the E3 zinc and ring finger 1 promotes axon degeneration by targeting AKT to proteasomal degradation (Wakatsuki et al., 2011). Decline in AKT levels decreases glycogen synthase kinase- $3 \beta$ phosphorylation, thus converting it into its active form, which in turn destabilizes microtubule assembly, with concomitant loss of cytoskeleton integrity and thereby axon degeneration (Wakatsuki et al., 2011). Axon degeneration occurring during development, in particular the pruning of $\gamma$ neurons of Drosophila mushroom bodies, also relies on UPS machinery to modulate microtubule cytoskeleton (Watts et al., 2003; Wong et al., 2013). Despite this shared UPS effector, distinct molecular pathways underpin developmental axon degeneration and Wallerian degeneration (for an informative discussion of this issue, see Geden and Deshmukh, 2016), and hence the pending need to identify the ubiquitin-related players involved in developmental regulated pruning. Finally, proteasome clearance can trigger Wallerian degeneration by launching axonal autophagy. MCL1, a BCL2 family member, acts as a break on axonal autophagy because of the sequestering of the autophagy regulator BECLIN1. Glycogen synthase kinase- $3 \beta$ phosphorylates MCL1, which is then ubiquitinated by the E3 ligase FBXW7 and targeted to proteolysis, thus relieving the constraint on BECLIN1 (Wakatsuki et al., 2017). Overall, ubiquitin seems to act on several fronts to coordinate axon degeneration: either at the triggering phase through modulation of NMNAT2 or at the executing phase through disintegration of microtubules and autophagy.

The prominent role of ubiquitin signaling in both the assembly (discussed in sections Axon specification, Axon outgrowth, Axon guidance, and Presynapse formation) and pruning of axonal domains strongly suggests its involvement in the refinement of neuronal circuit during development. Thus, the high prevalence of axonal ubiquitin dysfunction as a causative factor in neurodevelopmental diseases (discussed in the next section) is not surprising.

\section{When ubiquitin signaling goes awry in axons}

Dysfunction of the UPS is thought to underlie several neurologic disorders. In the brain, the proteasome and ubiquitin control diverse functions, including serving as key regulators of neuronal protein homeostasis (Tai and Schuman, 2008; Bingol and Sheng, 2011). Therefore, not surprisingly, UPS dysfunction has been closely linked to neurodegenerative diseases, such as Alzheimer's disease, Parkinson's disease, amyotrophic lateral sclerosis, or Huntington's disease. Generally speaking, neurodegenerative diseases are characterized by aberrant accumulation of ubiquitin-rich intracellular protein aggregates (Perry et al., 1987; Lowe et al., 1988; Davies et al., 1997). This can stem from mutations or dysfunctions of UPS proteins (Kitada et al., 1998; Leroy et al., 1998; Van Leeuwen et al., 1998) or from saturation or deterioration of UPS clearance capacity by abnormal protein loads (Bence et al., 2001; Keck et al., 2003; Lindersson et al., 2004). In addition, impairments in the ubiquitination cascade can alter specific neuronal mechanisms into generating pathogenic phenotypes as it is the case of neurodevelopmental disorders. Because this review examines ubiquitin involvement in axon development and function, we will focus the remainder of this section on how aberrant ubiquitin signaling leads to axonal dysfunction and contributes to the pathogenesis of specific neurologic conditions.

Mutations in ubiquitination enzymes are linked to presynaptic dysfunctions in neurodevelopmental diseases. In X-linked infantile spinal-muscular atrophy (SMA), characterized by severe muscle atrophy and premature death, mutations in the gene encoding the E1 ubiquitin-activating enzyme UBA1 were reported (Ramser et al., 2008). Similarly, Type I-III SMA, caused by loss of survival motor neuron protein (Lefebvre et al., 1995), also has reduced levels of UBA1 and therefore disrupted ubiquitin homeostasis (Wishart et al., 2014). Importantly, UBA1 deficiency was shown to directly contribute to axonal and synaptic neuromuscular pathogenesis in zebrafish, Drosophila, and mouse models of SMA (Wishart et al., 2014), and these were rescued by restoration of UBA1 levels, with concomitant improvement in motor performance (Powis et al., 2016). This suggests that anomalous ubiquitin dynamics at the axonal level is likely to contribute to the onset of several forms of SMA.

Mutations in E3 ligases are also implicated in neurologic conditions. For instance, the E3 UBE3A has been implicated in the pathogenesis of autism, Rett syndrome (Makedonski et al., 2005), and schizophrenia (Kohlbrenner et al., 2018). UBE3A is also lost in Angelman syndrome (AS) (Kishino et al., 1997; Matsuura et al., 1997), which is characterized by developmental delay and intellectual and motor disability (Angelman, 1965). AS mouse models show deficits in learning and impairments in synaptic maturation, transmission, and plasticity (Jiang et al., 1998; Yashiro et al., 2009; Wallace et al., 2012). The fact that UBE3A is present at presynaptic terminals (Dindot et al., 2008) suggests that AS pathology may emerge from axonal dysfunction. Indeed, defects in axon guidance (Tonazzini et al., 2019), presynaptic development ( $\mathrm{Li}$ et al., 2016), and presynaptic vesicle cycling (Wallace et al., 2012) are observed with AS-like UBE3A loss. In addition, the increased susceptibility of AS patients to seizures likely results from augmented intrinsic neuronal excitability because of impaired UBE3A-mediated degradation of calcium and voltage-dependent big potassium channels (Sun et al., 2019), which are located in axons and presynaptic terminals (Misonou et al., 2006). Interestingly, presynaptic formation is also regulated by the autism-linked E3 ligase RNF8 (Valnegri et al., 2017) (Fig. $3 A$ ), leading to the speculation that ubiquitin-driven presynaptic dysregulation is a common pathogenic mechanism in AS and autism. The involvement of E3 ligases in presynaptic function and subsequent disease progression is further reinforced by studies in the tambaleante mutant mouse. These animals carry a 
spontaneous mutation in the E3 HERC1 (Mashimo et al., 2009), a protein that is also mutated in cases of intellectual disability (Nguyen et al., 2016; Utine et al., 2017). Tambaleante mice exhibit severe ataxia and neuronal degeneration (Mashimo et al., 2009), which is preceded by presynaptic dysfunction at the NMJ (Bachiller et al., 2015).

Dysfunction of ubiquitin decoding systems in axons may also contribute to disease expression. A point mutation in the proteasome shuttle UBQLN4, identified in familial amyotrophic lateral sclerosis, was found to cause aberrant axon branching because of inappropriate proteolysis of $\beta$-catenin (Edens et al., 2017). Moreover, mutations in the ubiquitin-binding protein phospholipase A2-activating protein were shown to cause a lethal infantile epileptic encephalopathy by disrupting the endolysosomal trafficking of K63-polyubiquitinated proteins at the presynapse, leading to impaired presynaptic release (Hall et al., 2017).

Finally, abnormal function of deubiquitinases has also been linked to the etiology of neurologic conditions. A spontaneously arising loss-of-function mutation in the deubiquitinase USP14 has been shown to underlie ataxia in $a x^{J}$ mice. These animals exhibit severe resting tremor at 2-3 weeks old, followed by hindlimb paralysis and death early in development (Wilson et al., 2002). USP14 recycles ubiquitin from substrates before their proteasome removal, and therefore levels of monomeric ubiquitin are reduced in brain tissue of the mutant mice (Anderson et al., 2005). In addition, these mice display severe presynaptic structural and functional defects at the NMJ that are rescued by neuron-specific overexpression of ubiquitin (Chen et al., 2009, 2011). These findings indicate that fluctuations in synaptic ubiquitin levels may lead to the development of synaptic anomalies. This hypothesis is further fortified by analysis of the gracile axonal dystrophy mice, which have a spontaneous mutation in the deubiquitinase UCH-L1 (Saigoh et al., 1999) and exhibit severe sensory ataxia at early stages, as a result of axonal degeneration in the gracile tract (Kikuchi et al., 1990). Similarly to the ataxia $a x^{J}$ mice, these animals have reduced levels of monomeric ubiquitin (Osaka et al., 2003). Moreover, alterations of synaptic structure by $\mathrm{UCH}-\mathrm{L} 1$ inhibition are reversed by ubiquitin overexpression (Cartier et al., 2009). Interestingly, loss-of-function genetic modifications (Leroy et al., 1998), reduced levels (Choi et al., 2004; Barrachina et al., 2006), and post-translational modifications (Choi et al., 2004; Z. Liu et al., 2009) in UCH-L1 have been linked to Alzheimer's and Parkinson's disease, thus further reinforcing that the inability to maintain steady-state levels of neuronal ubiquitin is likely to underlie emergence of neurologic defects.

Mutations in another deubiquitinase, the ubiquitin-specific peptidase 9 X-linked (USP9X), and in its target protein PRICKLE (Paemka et al., 2015), have been identified in epileptic patients (Bassuk et al., 2008; Tao et al., 2011; Paemka et al., 2015). PRICKLE promotes axon outgrowth (Mrkusich et al., 2011) and regulates axonal vesicle transport (Ehaideb et al., 2014). In flies, a PRICKLE loss-of-function mutation increases predisposition for seizures, which are repressed by pharmacological or genetic inhibition of USP9X (Tao et al., 2011; Paemka et al., 2015). Importantly, such seizure-prone phenotype results from alterations in axonal transport (Ehaideb et al., 2014), supporting that PRICKLE-USP9X axonal interaction is an important pathway in controlling seizures.

Another example of pathogenic deficits in deubiquitination in the early stages of disease occurs in the muscle weakening disorder myotonic dystrophy Type 1. In diseased brains, exacerbated deubiquitination of MBNL1 resulting from expanded CUG RNA (a disease hallmark) results in translocation of the protein from the cytoplasm to the nucleus (Wang et al., 2018). As a result, the axon growth-promoting function of cytoplasmic MBNL1 (previously discussed in Axon outgrowth; see Fig. 2C) is abrogated (Wang et al., 2018), which can partly explain the neurite degeneration observed at early disease stages (Wang et al., 2017). Together, these findings indicate that anomalous ubiquitin signaling at the axonal level is likely to contribute, at least partially, to the pathophysiology of diverse brain disorders, with a particular emphasis on neurodevelopmental diseases. This substantial prevalence as a causative factor for the pathogenesis of neurologic diseases highlights the need to fully understand and characterize the physiological function of the proteasome and ubiquitin in distinct neuronal compartments.

Remarkable insight into the diseased brain has been provided by the identification of causative mutations and follow-up studies unraveling the corresponding protein function. As discussed above, this approach has been particularly prolific to the neuronal ubiquitin field. It may, however, neglect the putative involvement of ubiquitin signaling to the etiology of diseases free of ubiquitin-related genetic abnormalities. A dysfunctional neuronal network may increase the burden on housekeeping mechanisms (e.g., the UPS, but also protein translation and quality control, mitochondrial ATP production, intracellular trafficking, etc.), thus affecting their local homeostasis and concomitantly worsening the disease phenotype and progression. We therefore predict that understanding how local ubiquitin signaling is altered in diseased neurons could reveal a broader impact of ubiquitin in pathology, particularly in conditions of unbalanced homeostasis, such as stress, depression, or aging.

\section{Conclusion}

In conclusion, overall, mounting data demonstrate that ubiquitin signaling, in most cases culminating in proteasome degradation of tagged proteins, operates in axons from the beginning of their differentiation to the establishment of proper presynaptic transmission (Figs. 2, 3). In addition to the list of ubiquitin and/or proteasome targets summarized in Table 1, whose selective (de) ubiquitination has been shown to exert direct roles in axonal events, many other axonal molecules, including signaling, synaptic vesicles, and active zone proteins, are known to be post-translationally regulated in such fashion (Table 2). It is thus possible that ubiquitin influences axon-related events in countless other ways that are yet to be identified.

A question remains as to whether and how ubiquitin pathways are locally modulated. In other words, do axons control ubiquitin signaling? It is fair to believe they do. Surely axonal control of ubiquitin and proteolytic machinery would guarantee effective exploitation of ubiquitin power to spatiotemporally meet the particular demands of an axon. First glimpses into this issue indeed show that presynaptic proteins can modulate the activity of E3 ligases (Ding et al., 2007; Waites et al., 2013; Del Prete et al., 2016). Similarly, in dendrites, proteasome activity and localization can be regulated by postsynaptic CaMKII $\alpha$ (Bingol et al., 2010). A broader picture of such bidirectional regulation awaits future efforts.

While information on the proteins involved in ubiquitination is solidly growing (Tables 1 and 2), the axonal machinery engaged in downstream decoding and translation of ubiquitin signals remains elusive. The same holds true for local proteasome regulators and shuttles. Of note, the fact that ubiquitin-binding domains were identified in presynaptic proteins (Polo et al., 2002; Stamenova et al., 2007; Okumura et al., 2011) suggests a 
layer of presynaptic ubiquitin-related modulation that has so far evaded us. Last, but definitely not least, it would be of great value to better grasp whether and how axonal translation (Cioni et al., 2018) and ubiquitin-dependent degradation act jointly in the control of axonal biology. A high degree of interdependence is indeed expected: axonally translated proteins are the main targets of UPS (Deglincerti et al., 2015), which in turn can control the levels of ribosomes in axons (Costa et al., 2019). Together, future research in the field will undoubtedly improve our understanding of neurologic disorders featuring deficits in axonal ubiquitin signaling and hence abnormal neuronal function.

\section{References}

Aberle H, Haghighi AP, Fetter RD, McCabe BD, Magalhães TR, Goodman CS (2002) Wishful thinking encodes a BMP type II receptor that regulates synaptic growth in Drosophila. Neuron 33:545-558.

Anckar J, Bonni A (2015) Regulation of neuronal morphogenesis and positioning by ubiquitin-specific proteases in the cerebellum. PLoS One 10: e0117076.

Anderson C, Crimmins S, Wilson JA, Korbel GA, Ploegh HL, Wilson SM (2005) Loss of Usp14 results in reduced levels of ubiquitin in ataxia mice. J Neurochem 95:724-731.

Angelman H (1965) 'Puppet' Children a report on three cases. Dev Med Child Neurol 7:681-688.

Arévalo JC, Waite J, Rajagopal R, Beyna M, Chen ZY, Lee FS, Chao MV (2006) Cell survival through Trk neurotrophin receptors is differentially regulated by ubiquitination. Neuron 50:549-559.

Artinian J, McGauran AM, De Jaeger X, Mouledous L, Frances B, Roullet P (2008) Protein degradation, as with protein synthesis, is required during not only long-term spatial memory consolidation but also reconsolidation. Eur J Neurosci 27:3009-3019.

Bachiller S, Rybkina T, Porras-García E, Pérez-Villegas E, Tabares L, Armengol JA, Carrión AM, Ruiz R (2015) The HERC1 E3 ubiquitin ligase is essential for normal development and for neurotransmission at the mouse neuromuscular junction. Cell Mol Life Sci 72:2961-2971.

Bae S, Kim SY, Jung JH, Yoon Y, Cha HJ, Lee H, Kim K, Kim J, An IS, Kim J, Um HD, Park IC, Lee SJ, Nam SY, Jin YW, Lee JH, An S (2012) Akt is negatively regulated by the MULAN E3 ligase. Cell Res 22:873-885.

Baker R, Lewis SM, Sasaki AT, Wilkerson EM, Locasale JW, Cantley LC, Kuhlman B, Dohlman HG, Campbell SL (2013) Site-specific monoubiquitination activates Ras by impeding GTPase-activating protein function. Nat Struct Mol Biol 20:46-52.

Bao H, Reist NE, Zhang B (2008) The Drosophila epsin 1 is required for ubiquitin-dependent synaptic growth and function but not for synaptic vesicle recycling. Traffic 9:2190-2205.

Barrachina M, Castaño E, Dalfó E, Maes T, Buesa C, Ferrer I (2006) Reduced ubiquitin C-terminal hydrolase-1 expression levels in dementia with Lewy bodies. Neurobiol Dis 22:265-273.

Bassuk AG, Wallace RH, Buhr A, Buller AR, Afawi Z, Shimojo M, Miyata S, Chen S, Gonzalez-Alegre P, Griesbach HL, Wu S, Nashelsky M, Vladar EK, Antic D, Ferguson PJ, Cirak S, Voit T, Scott MP, Axelrod JD, Gurnett C, et al. (2008) A homozygous mutation in human PRICKLE1 causes an autosomal-recessive progressive myoclonus epilepsy-ataxia syndrome. Am J Hum Genet 83:572-581.

Bedford L, Layfield R, Mayer RJ, Peng J, Xu P (2011) Diverse polyubiquitin chains accumulate following $26 \mathrm{~S}$ proteasomal dysfunction in mammalian neurones. Neurosci Lett 491:44-47.

Bence NF, Sampat RM, Kopito RR (2001) Impairment of the ubiquitin-proteasome system by protein aggregation. Science 292:1552-1555.

Bhat JM, Pan J, Hutter H (2015) PLR-1, a putative E3 ubiquitin ligase, controls cell polarity and axonal extensions in C. elegans. Dev Biol 398:4456.

Bhattacharyya BJ, Wilson SM, Jung H, Miller RJ (2012) Altered neurotransmitter release machinery in mice deficient for the deubiquitinating enzyme Usp14. Am J Physiol Cell Physiol 302:C698-C708.

Bingol B, Schuman EM (2006) Activity-dependent dynamics and sequestration of proteasomes in dendritic spines. Nature 441:1144-1148.

Bingol B, Sheng M (2011) Deconstruction for reconstruction: the role of proteolysis in neural plasticity and disease. Neuron 69:22-32.
Bingol B, Wang CF, Arnott D, Cheng D, Peng J, Sheng M (2010) Autophosphorylated CaMKIIalpha acts as a scaffold to recruit proteasomes to dendritic spines. Cell 140:567-578.

Bloom AJ, Miller BR, Sanes JR, DiAntonio A (2007) The requirement for Phr1 in CNS axon tract formation reveals the corticostriatal boundary as a choice point for cortical axons. Genes Dev 21:2593-2606.

Bórquez DA, González-Billault C (2011) Regulation of cell polarity by controlled proteolytic systems. Biol Res 44:35-41.

Boutet SC, Disatnik MH, Chan LS, Iori K, Rando TA (2007) Regulation of Pax3 by proteasomal degradation of monoubiquitinated protein in skeletal muscle progenitors. Cell 130:349-362.

Brace EJ, Wu C, Valakh V, DiAntonio A (2014) SkpA restrains synaptic terminal growth during development and promotes axonal degeneration following injury. J Neurosci 34:8398-8410.

Burgess RW, Peterson KA, Johnson MJ, Roix JJ, Welsh IC, O'Brien TP (2004) Evidence for a conserved function in synapse formation reveals $\mathrm{Phrl}$ as a candidate gene for respiratory failure in newborn mice. Mol Cell Biol 24:1096-1105.

Campbell DS, Holt CE (2001) Chemotropic responses of retinal growth cones mediated by rapid local protein synthesis and degradation. Neuron 32:1013-1026.

Cartier AE, Djakovic SN, Salehi A, Wilson SM, Masliah E, Patrick GN (2009) Regulation of synaptic structure by ubiquitin C-terminal hydrolase L1. J Neurosci 29:7857-7868.

Chen H, Polo S, Paolo P, Fiore D, Camilli PD (2003) Rapid $\mathrm{Ca}^{2+}$-dependent decrease of protein ubiquitination at synapses. Proc Natl Acad Sci USA 100:14908-14913.

Chen PC, Qin LN, Li XM, Walters BJ, Wilson JA, Mei L, Wilson SM (2009) The proteasome-associated deubiquitinating enzyme Usp14 is essential for the maintenance of synaptic ubiquitin levels and the development of neuromuscular junctions. J Neurosci 29:10909-10919.

Chen PC, Bhattacharyya BJ, Hanna J, Minkel H, Wilson JA, Finley D, Miller RJ, Wilson SM (2011) Ubiquitin homeostasis is critical for synaptic development and function. J Neurosci 31:17505-17513.

Cheng P, Lu H, Shelly M, Gao H, Poo M (2011a) Phosphorylation of E3 ligase Smurf1 switches its substrate preference in support of axon development. Neuron 69:231-243.

Cheng PL, Song AH, Wong YH, Wang S, Zhang X, Poo MM (2011b) Selfamplifying autocrine actions of BDNF in axon development. Proc Natl Acad Sci USA 108:18430-18435.

Chin LS, Vavalle JP, Li L (2002) Staring, a novel E3 ubiquitin-protein ligase that targets syntaxin 1 for degradation. J Biol Chem 277:35071-35079.

Choi J, Levey AI, Weintraub ST, Rees HD, Gearing M, Chin LS, Li L (2004) Oxidative modifications and down-regulation of ubiquitin carboxyl-terminal hydrolase L1 associated with idiopathic Parkinson's and Alzheimer's diseases. J Biol Chem 279:13256-13264.

Christie KJ, Martinez JA, Zochodne DW (2012) Disruption of E3 ligase NEDD4 in peripheral neurons interrupts axon outgrowth: linkage to PTEN. Mol Cell Neurosci 50:179-192.

Ciani L, Krylova O, Smalley MJ, Dale TC, Salinas PC (2004) A divergent canonical WNT-signaling pathway regulates microtubule dynamics: dishevelled signals locally to stabilize microtubules. J Cell Biol 164:243-253.

Cioni JM, Koppers M, Holt CE (2018) Molecular control of local translation in axon development and maintenance. Curr Opin Neurobiol 51:86-94.

Colledge M, Snyder EM, Crozier RA, Soderling JA, Jin Y, Langeberg LK, Lu H, Bear MF, Scott JD (2003) Ubiquitination regulates PSD-95 degradation and AMPA receptor surface expression. Neuron 40:595-607.

Collins CA, Wairkar YP, Johnson SL, DiAntonio A (2006) Highwire restrains synaptic growth by attenuating a MAP kinase signal. Neuron 51:57-69.

Costa RO, Martins H, Martins LF, Cwetsch AW, Mele M, Pedro JR, Tomé D, Jeon NL, Cancedda L, Jaffrey SR, Almeida RD (2019) Synaptogenesis stimulates a proteasome-mediated ribosome reduction in axons. Cell Rep 28:864-876.e6.

Davies SW, Turmaine M, Cozens BA, DiFiglia M, Sharp AH, Ross CA, Scherzinger E, Wanker EE, Mangiarini L, Bates GP (1997) Formation of neuronal intranuclear inclusions underlies the neurological dysfunction in mice transgenic for the HD mutation. Cell 90:537-548.

Deglincerti A, Liu Y, Colak D, Hengst U, Xu G, Jaffrey SR (2015) Coupled local translation and degradation regulate growth cone collapse. Nat Commun 6:6888

Del Prete D, Rice RC, Rajadhyaksha AM, D’Adamio L (2016) Amyloid precursor protein (APP) may act as a substrate and a recognition unit for 
CRL4CRBN and Stub1 E3 ligases facilitating ubiquitination of proteins involved in presynaptic functions and neurodegeneration. J Biol Chem 291:17209-17227.

Deng L, Wang C, Spencer E, Yang L, Braun A, You J, Slaughter C, Pickart C, Chen ZJ (2000) Activation of the I $\kappa$ b kinase complex by TRAF6 requires a dimeric ubiquitin-conjugating enzyme complex and a unique polyubiquitin chain. Cell 103:351-361.

DiAntonio A, Haghighi AP, Portman SL, Lee JD, Amaranto AM, Goodman CS (2001) Ubiquitination-dependent mechanisms regulate synaptic growth and function. Nature 412:449-452.

Dimitrova YN, Li J, Lee YT, Rios-Esteves J, Friedman DB, Choi HJ, Weis WI, Wang CY, Chazin WJ (2010) Direct ubiquitination of beta-catenin by Siah-1 and regulation by the exchange factor TBL1. J Biol Chem 285:13507-13516.

Dindot SV, Antalffy BA, Bhattacharjee MB, Beaudet AL (2008) The Angelman syndrome ubiquitin ligase localizes to the synapse and nucleus, and maternal deficiency results in abnormal dendritic spine morphology. Hum Mol Genet 17:111-118.

Ding M, Chao D, Wang G, Shen K (2007) Spatial regulation of an E3 ubiquitin ligase directs selective synapse elimination. Science 317:947-951.

Drinjakovic J, Jung H, Campbell DS, Strochlic L, Dwivedy A, Holt CE (2010) E3 ligase Nedd4 promotes axon branching by downregulating PTEN. Neuron 65:341-357.

Dupont S, Mamidi A, Cordenonsi M, Montagner M, Zacchigna L, Adorno M, Martello G, Stinchfield MJ, Soligo S, Morsut L, Inui M, Moro S, Modena N, Argenton F, Newfeld SJ, Piccolo S (2009) FAM/USP9x, a deubiquitinating enzyme essential for TGF $\beta$ signaling, controls Smad4 monoubiquitination. Cell 136:123-135.

Dupraz S, Grassi D, Karnas D, Nieto Guil AF, Hicks D, Quiroga S (2013) The insulin-like growth factor 1 receptor is essential for axonal regeneration in adult central nervous system neurons. PLoS One 8:e54462.

Edens BM, Yan J, Miller N, Deng HX, Siddique T, Ma YC (2017) A novel ALS-associated variant in UBQLN4 regulates motor axon morphogenesis. Elife 6:e25453.

Ehaideb SN, Iyengar A, Ueda A, Iacobucci C, Cranston GJ, Bassuk AG, Gubb D, Axelrod JD, Gunawardena S, Wu CF, Manak JR (2014) Prickle modulates microtubule polarity and axonal transport to ameliorate seizures in flies. Proc Natl Acad Sci USA 111:11187-11192.

Ehlers MD (2003) Activity level controls postsynaptic composition and signaling via the ubiquitin-proteasome system. Nat Neurosci 6:231-242.

Elsasser S, Finley D (2005) Delivery of ubiquitinated substrates to proteinunfolding machines. Nat Cell Biol 7:742-749.

Fallon L, Bélanger CM, Corera AT, Kontogiannea M, Regan-Klapisz E, Moreau F, Voortman J, Haber M, Rouleau G, Thorarinsdottir T, Brice A, van Bergen En Henegouwen PM, Fon EA (2006) A regulated interaction with the UIM protein Eps15 implicates parkin in EGF receptor trafficking and PI(3)K-Akt signalling. Nat Cell Biol 8:834-842.

Fei C, Li Z, Li C, Chen Y, Chen Z, He X, Mao L, Wang X, Zeng R, Li L (2013) Smurf1-mediated Lys29-linked nonproteolytic polyubiquitination of axin negatively regulates Wnt/ $\beta$-catenin signaling. Mol Cell Biol 33:4095-4105.

Ferrara NC, Jarome TJ, Cullen PK, Orsi SA, Kwapis JL, Trask S, Pullins SE, Helmstetter FJ (2019) GluR2 endocytosis-dependent protein degradation in the amygdala mediates memory updating. Sci Rep 9:5180.

Ferron L, Nieto-Rostro M, Cassidy JS, Dolphin AC (2014) Fragile X mental retardation protein controls synaptic vesicle exocytosis by modulating $\mathrm{N}$ type calcium channel density. Nat Commun 5:3628.

Flach K, Ramminger E, Hilbrich I, Arsalan-Werner A, Albrecht F, Herrmann L, Goedert M, Arendt T, Holzer M (2014) Axotrophin/MARCH7 acts as an E3 ubiquitin ligase and ubiquitinates tau protein in vitro impairing microtubule binding. Biochim Biophys Acta 1842:1527-1538.

Franco M, Seyfried NT, Brand AH, Peng J, Mayor U (2011) A novel strategy to isolate ubiquitin conjugates reveals wide role for ubiquitination during neural development. Mol Cell Proteomics 10:M110.002188.

Geden MJ, Deshmukh M (2016) Axon degeneration: context defines distinct pathways. Curr Opin Neurobiol 39:108-115.

Georgieva MV, De Pablo Y, Sanchis D, Comella JX, Llovera M (2011) Ubiquitination of TrkA by Nedd4-2 regulates receptor lysosomal targeting and mediates receptor signaling. J Neurochem 117:479-493.

Gorla M, Santiago C, Chaudhari K, Layman AA, Oliver PM, Bashaw GJ (2019) Ndfip proteins target Robo receptors for degradation and allow commissural axons to cross the midline in the developing spinal cord. Cell Rep 26:3298-3312.e4.

Haglund K, Sigismund S, Polo S, Szymkiewicz I, Di Fiore PP, Dikic I (2003) Multiple monoubiquitination of RTKs is sufficient for their endocytosis and degradation. Nat Cell Biol 5:461-466.

Hakim V, Cohen LD, Zuchman R, Ziv T, Ziv NE (2016) The effects of proteasomal inhibition on synaptic proteostasis. EMBO J 35:2238-2262.

Hall AC, Lucas FR, Salinas PC (2000) Axonal remodeling and synaptic differentiation in the cerebellum is regulated by WNT-7a signaling. Cell 100:525-535.

Hall EA, Nahorski MS, Murray LM, Shaheen R, Perkins E, Dissanayake KN, Kristaryanto Y, Jones RA, Vogt J, Rivagorda M, Handley MT, Mali GR, Quidwai T, Soares DC, Keighren MA, McKie L, Mort RL, Gammoh N, Garcia-Munoz A, Davey T, et al. (2017) PLAA mutations cause a lethal infantile epileptic encephalopathy by disrupting ubiquitin-mediated endolysosomal degradation of synaptic proteins. Am J Hum Genet 100:706-724.

Hamilton AM, Oh WC, Vega-Ramirez H, Stein IS, Hell JW, Patrick GN, Zito $\mathrm{K}$ (2012) Activity-dependent growth of new dendritic spines is regulated by the proteasome. Neuron 74:1023-1030.

Hao HX, Xie Y, Zhang Y, Charlat O, Oster E, Avello M, Lei H, Mickanin C, Liu D, Ruffner H, Mao X, Ma Q, Zamponi R, Bouwmeester T, Finan PM, Kirschner MW, Porter JA, Serluca FC, Cong F (2012) ZNRF3 promotes Wnt receptor turnover in an R-spondin-sensitive manner. Nature 485:195-202.

Haugsten EM, Malecki J, Bjørklund SM, Olsnes S, Wesche J (2008) Ubiquitination of fibroblast growth factor receptor 1 is required for its intracellular sorting but not for its endocytosis. Mol Biol Cell 19:33903403.

Hay-Koren A, Caspi M, Zilberberg A, Rosin-Arbesfeld R (2011) The EDD E3 ubiquitin ligase ubiquitinates and up-regulates beta-catenin. Mol Biol Cell 22:399-411.

Hendricks M, Jesuthasan S (2009) PHR regulates growth cone pausing at intermediate targets through microtubule disassembly. J Neurosci 29:65936598.

Hu G, Zhang S, Vidal M, Baer JL, Xu T, Fearon ER (1997) Mammalian homologs of seven in absentia regulate DCC via the ubiquitin-proteasome pathway. Genes Dev 11:2701-2714.

Husnjak K, Dikic I (2012) Ubiquitin-binding proteins: decoders of ubiquitinmediated cellular functions. Annu Rev Biochem 81:291-322.

Ikeuchi Y, Stegmüller J, Netherton S, Huynh MA, Masu M, Frank D, Bonni S, Bonni A (2009) A SnoN-Ccd1 pathway promotes axonal morphogenesis in the mammalian brain. J Neurosci 29:4312-4321.

Ilardi JM, Mochida S, Sheng ZH (1999) Snapin: a SNARE-associated protein implicated in synaptic transmission. Nat Neurosci 2:119-124.

Ing B, Shteiman-Kotler A, Castelli M, Henry P, Pak Y, Stewart B, Boulianne GL, Rotin D (2007) Regulation of Commissureless by the ubiquitin ligase DNedd4 is required for neuromuscular synaptogenesis in Drosophila melanogaster. Mol Cell Biol 27:481-496.

Jackson SP, Durocher D (2013) Regulation of DNA damage responses by ubiquitin and SUMO. Mol Cell 49:795-807.

James G, Key B, Beverdam A (2014) The E3 ubiquitin ligase Mycbp2 genetically interacts with Robo2 to modulate axon guidance in the mouse olfactory system. Brain Struct Funct 219:861-874.

Jarome TJ, Helmstetter FJ (2013) The ubiquitin-proteasome system as a critical regulator of synaptic plasticity and long-term memory formation. Neurobiol Learn Mem 105:107-116.

Jarome TJ, Werner CT, Kwapis JL, Helmstetter FJ (2011) Activity dependent protein degradation is critical for the formation and stability of fear memory in the amygdala. PLoS One 6:e24349.

Jespersen T, Membrez M, Nicolas CS, Pitard B, Staub O, Olesen SP, Baró I, Abriel H (2007) The KCNQ1 potassium channel is down-regulated by ubiquitylating enzymes of the Nedd4/Nedd4-like family. Cardiovasc Res 74:64-74.

Jiang H, Guo W, Liang X, Rao Y (2005) Both the establishment and the maintenance of neuronal polarity require active mechanisms: critical roles of GSK-3beta and its upstream regulators. Cell 120:123-135.

Jiang Y, Armstrong D, Albrecht U, Atkins C, Noebels J, Eichele G, Sweatt J, Beaudet A (1998) Mutation of the Angelman ubiquitin ligase in mice causes increased cytoplasmic p53 and deficits of contextual learning and long-term potentiation. Neuron 21:799-811. 
Jiménez C, Portela RA, Mellado M, Rodríguez-Frade JM, Collard J, Serrano A, Martínez-A C, Avila J, Carrera AC (2000) Role of the PI3K regulatory subunit in the control of actin organization and cell migration. J Cell Biol 151:249-262.

Jin L, Williamson A, Banerjee S, Philipp I, Rape M (2008) Mechanism of ubiquitin-chain formation by the human anaphase-promoting complex. Cell 133:653-665.

Kabayama H, Tokushige N, Takeuchi M, Kabayama M, Fukuda M, Mikoshiba K (2017) Parkin promotes proteasomal degradation of synaptotagmin IV by accelerating polyubiquitination. Mol Cell Neurosci 80:89-99.

Kaiser SE, Riley BE, Shaler TA, Trevino RS, Becker CH, Schulman H, Kopito RR (2011) Protein standard absolute quantification (PSAQ) method for the measurement of cellular ubiquitin pools. Nat Methods 8:691-696.

Kannan M, Lee SJ, Schwedhelm-Domeyer N, Stegmüller J (2012) The E3 ligase Cdh1-anaphase promoting complex operates upstream of the E3 ligase Smurf1 in the control of axon growth. Development 139:36003612 .

Kato A, Rouach N, Nicoll RA, Bredt DS (2005) Activity-dependent NMDA receptor degradation mediated by retrotranslocation and ubiquitination. Proc Natl Acad Sci USA 102:5600-5605.

Keck S, Nitsch R, Grune T, Ullrich O (2003) Proteasome inhibition by paired helical filament-tau in brains of patients with Alzheimer's disease. J Neurochem 85:115-122.

Kidd T, Bland KS, Goodman CS (1999) Slit is the midline repellent for the Robo receptor in Drosophila. Cell 96:785-794.

Kidd T, Russell C, Goodman CS, Tear G (1998) Dosage-sensitive and complementary functions of roundabout and Commissureless control axon crossing of the CNS midline. Neuron 20:25-33.

Kikuchi T, Mukoyama M, Yamazaki K, Moriya H (1990) Axonal degeneration of ascending sensory neurons in gracile axonal dystrophy mutant mouse. Acta Neuropathol 80:145-151.

Kim TH, Lee HK, Seo IA, Bae HR, Suh DJ, Wu J, Rao Y, Hwang KG, Park HT (2005) Netrin induces down-regulation of its receptor, Deleted in Colorectal Cancer, through the ubiquitin-proteasome pathway in the embryonic cortical neuron. J Neurochem 95:1-8.

Kimura Y, Yashiroda H, Kudo T, Koitabashi S, Murata S, Kakizuka A, Tanaka K (2009) An inhibitor of a deubiquitinating enzyme regulates ubiquitin homeostasis. Cell 137:549-559.

Kish-Trier E, Hill CP (2013) Structural biology of the proteasome. Annu Rev Biophys 42:29-49.

Kishino T, Lalande M, Wagstaff J (1997) UBE3A/E6-AP mutations cause Angelman syndrome. Nat Genet 15:70-73.

Kitada T, Asakawa S, Hattori N, Matsumine H, Yamamura Y, Minoshima S, Yokochi M, Mizuno Y, Shimizu N (1998) Mutations in the parkin gene cause autosomal recessive juvenile parkinsonism. Nature 392:605-608.

Ko HR, Kwon IS, Hwang I, Jin EJ, Shin JH, Brennan-Minnella AM, Swanson R, Cho SW, Lee KH, Ahn JY (2016) Akt1-inhibitor of DNA binding2 is essential for growth cone formation and axon growth and promotes central nervous system axon regeneration. Elife 5:21.

Koga K, Yao I, Setou M, Zhuo M (2017) SCRAPPER selectively contributes to spontaneous release and presynaptic long-term potentiation in the anterior cingulate cortex. J Neurosci 37:3887-3895.

Kohlbrenner EA, Shaskan N, Pietersen CY, Sonntag KC, Woo TU (2018) Gene expression profile associated with postnatal development of pyramidal neurons in the human prefrontal cortex implicates ubiquitin ligase E3 in the pathophysiology of schizophrenia onset. J Psychiatr Res 102:110-117.

Komander D, Rape M (2012) The ubiquitin code. Annu Rev Biochem 81:203-229.

Komander D, Clague MJ, Urbé S (2009) Breaking the chains: structure and function of the deubiquitinases. Nat Rev Mol Cell Biol 10:550-563.

Konishi Y, Stegmüller J, Matsuda T, Bonni S, Bonni A (2004) Cdh1-APC controls axonal growth and patterning in the mammalian brain. Science 303:1026-1030.

Koo BK, Spit M, Jordens I, Low TY, Stange DE, Van De Wetering M, Van Es JH, Mohammed S, Heck AJ, Maurice MM, Clevers H (2012) Tumour suppressor RNF43 is a stem-cell E3 ligase that induces endocytosis of Wnt receptors. Nature 488:665-669.

Koprivica V, Cho KS, Park JB, Yiu G, Atwal J, Gore B, Kim JA, Lin E, Tessier-Lavigne M, Chen DF, He Z (2005) Neuroscience: EGFR activation mediates inhibition of axon regeneration by myelin and chondroitin sulfate proteoglycans. Science 310:106-110.

Kowalski JR, Dube H, Touroutine D, Rush KM, Goodwin PR, Carozza M, Didier Z, Francis MM, Juo P (2014) The Anaphase-Promoting Complex (APC) ubiquitin ligase regulates GABA transmission at the C. elegans neuromuscular junction. Mol Cell Neurosci 58:62-75.

Kravtsova-Ivantsiv Y, Cohen S, Ciechanover A (2009) Modification by single ubiquitin moieties rather than polyubiquitination is sufficient for proteasomal processing of the p105 NF- $\kappa$ B precursor. Mol Cell 33:496-504.

Krylova O, Messenger MJ, Salinas PC (2000) Dishevelled-1 regulates microtubule stability: a new function mediated by glycogen synthase kinase$3 \beta$. J Cell Biol 151:83-93.

Lasorella A, Stegmüller J, Guardavaccaro D, Liu G, Carro MS, Rothschild G, de la Torre-Ubieta L, Pagano M, Bonni A, Iavarone A (2006) Degradation of Id 2 by the anaphase-promoting complex couples cell cycle exit and axonal growth. Nature 442:471-474.

Laub M, Steppuhn JA, Blüggel M, Immler D, Meyer HE, Jennissen HP (1998) Modulation of calmodulin function by ubiquitin-calmodulin ligase and identification of the responsible ubiquitylation site in vertebrate calmodulin. Eur J Biochem 255:422-431.

Lazarevic V, Schöne C, Heine M, Gundelfinger ED, Fejtova A (2011) Extensive remodeling of the presynaptic cytomatrix upon homeostatic adaptation to network activity silencing. J Neurosci 31:10189-10200.

Lebrand C, Dent EW, Strasser GA, Lanier LM, Krause M, Svitkina TM, Borisy GG, Gertler FB (2004) Critical role of Ena/VASP proteins for filopodia formation in neurons and in function downstream of netrin-1. Neuron 42:37-49.

Lee S, Park S, Lee H, Han S, Song JM, Han D, Suh YH (2019) Nedd4 E3 ligase and beta-arrestins regulate ubiquitination, trafficking, and stability of the mGlu7 receptor. Elife 8:e44502.

Lee SH, Choi JH, Lee N, Lee HR, Kim JI, Yu NK, Choi SL, Lee SH, Kim H, Kaang BK (2008) Synaptic protein degradation underlies destabilization of retrieved fear memory. Science 319:1253-1256.

Lefebvre S, Bürglen L, Reboullet S, Clermont O, Burlet P, Viollet L, Benichou B, Cruaud C, Millasseau P, Zeviani M (1995) Identification and characterization of a spinal muscular atrophy-determining gene. Cell 80:155165.

Leroy E, Boyer R, Auburger G, Leube B, Ulm G, Mezey E, Harta G, Brownstein MJ, Jonnalagada S, Chernova T, Dehejia A, Lavedan C, Gasser T, Steinbach PJ, Wilkinson KD, Polymeropoulos MH (1998) The ubiquitin pathway in Parkinson's disease. Nature 395:451-452.

Lewcock JW, Genoud N, Lettieri K, Pfaff SL (2007) The ubiquitin ligase Phr1 regulates axon outgrowth through modulation of microtubule dynamics. Neuron 56:604-620

Li M, Brooks CL, Wu-Baer F, Chen D, Baer R, Gu W (2003) Mono- versus polyubiquitination: differential control of p53 fate by Mdm2. Science 302:1972-1975.

Li W, Yao A, Zhi H, Kaur K, Zhu YC, Jia M, Zhao H, Wang Q, Jin S, Zhao G, Xiong ZQ, Zhang YQ (2016) Angelman syndrome protein Ube3a regulates synaptic growth and endocytosis by inhibiting BMP signaling in Drosophila. PLoS Genet 12:e1006062.

Liani E, Eyal A, Avraham E, Shemer R, Szargel R, Berg D, Bornemann A, Riess O, Ross CA, Rott R, Engelender S (2004) Ubiquitylation of synphilin-1 and alpha-synuclein by SIAH and its presence in cellular inclusions and Lewy bodies imply a role in Parkinson's disease. Proc Natl Acad Sci USA 101:5500-5505.

Liao EH, Hung W, Abrams B, Zhen M (2004) An SCF-like ubiquitin ligase complex that controls presynaptic differentiation. Nature 430:345-350.

Lin MY, Lin YM, Kao T, Chuang HH, Chen RH (2011) PDZ-RhoGEF ubiquitination by Cullin3-KLHL20 controls neurotrophin-induced neurite outgrowth. J Cell Biol 193:985-994.

Lindersson E, Beedholm R, Højrup P, Moos T, Gai WP, Hendil KB, Jensen PH (2004) Proteasomal inhibition by $\alpha$-synuclein filaments and oligomers. J Biol Chem 279:12924-12934.

Liu C, Liu W, Ye Y, Li W (2017) Ufd2p synthesizes branched ubiquitin chains to promote the degradation of substrates modified with atypical chains. Nat Commun 8:14274.

Liu Y, Oppenheim RW, Sugiura Y, Lin W (2009) Abnormal development of the neuromuscular junction in Nedd4-deficient mice. Dev Biol 330:153166.

Liu Z, Meray RK, Grammatopoulos TN, Fredenburg RA, Cookson MR, Liu Y, Logan T, Lansbury PT (2009) Membrane-associated farnesylated 
UCH-L1 promotes alpha-synuclein neurotoxicity and is a therapeutic target for Parkinson's disease. Proc Natl Acad Sci USA 106:4635-4640.

Lowe J, Blanchard A, Morrell K, Lennox G, Reynolds L, Billett M, Landon M, Mayer RJ (1988) Ubiquitin is a common factor in intermediate filament inclusion bodies of diverse type in man, including those of Parkinson's disease, Pick's disease, and Alzheimer's disease, as well as Rosenthal fibres in cerebellar astrocytomas, cytoplasmic bodies in muscle, and Mallory bodies in alcoholic liver disease. J Pathol 155:9-15.

Makedonski K, Abuhatzira L, Kaufman Y, Razin A, Shemer R (2005) MeCP2 deficiency in Rett syndrome causes epigenetic aberrations at the PWS/AS imprinting center that affects UBE3A expression. Hum Mol Genet 14:1049-1058.

Marangoudakis S, Andrade A, Helton TD, Denome S, Castiglioni AJ, Lipscombe D (2012) Differential ubiquitination and proteasome regulation of $\mathrm{Ca}(\mathrm{V}) 2.2 \mathrm{~N}$-type channel splice isoforms. J Neurosci 32:1036510369.

Mashimo T, Hadjebi O, Amair-Pinedo F, Tsurumi T, Langa F, Serikawa T, Sotelo C, Guénet JL, Rosa JL (2009) Progressive Purkinje cell degeneration in tambaleante mutant mice is a consequence of a missense mutation in HERC1 E3 ubiquitin ligase. PLoS Genet 5:e1000784.

Matsuura T, Sutcliffe JS, Fang P, Galjaard RJ, Jiang YH, Benton CS, Rommens JM, Beaudet AL (1997) De novo truncating mutations in E6AP ubiquitin-protein ligase gene (UBE3A) in Angelman syndrome. Nat Genet 15:74-77.

McCabe BD, Marqués G, Haghighi AP, Fetter RD, Crotty ML, Haerry TE, Goodman CS, O'Connor MB (2003) The BMP homolog Gbb provides a retrograde signal that regulates synaptic growth at the Drosophila neuromuscular junction. Neuron 39:241-254.

McNally FJ, Vale RD (1993) Identification of katanin, an ATPase that severs and disassembles stable microtubules. Cell 75:419-429.

Menon S, Boyer NP, Winkle CC, McClain LM, Hanlin CC, Pandey D, Rothenfußer S, Taylor AM, Gupton SL (2015) The E3 ubiquitin ligase TRIM9 is a filopodia off switch required for netrin-dependent axon guidance. Dev Cell 35:698-712.

Misonou H, Menegola M, Buchwalder L, Park EW, Meredith A, Rhodes KJ, Aldrich RW, Trimmer JS (2006) Immunolocalization of the $\mathrm{Ca}^{2+}$-activated $\mathrm{K}^{+}$channel Slol in axons and nerve terminals of mammalian brain and cultured neurons. J Comp Neurol 496:289-302.

Moffat LL, Robinson RE, Bakoulis A, Clark SG (2014) The conserved transmembrane RING finger protein PLR-1 downregulates Wnt signaling by reducing Frizzled, Ror and Ryk cell-surface levels in C. elegans. Development 141:617-628.

Monami G, Emiliozzi V, Morrione A (2008) Grb10/Nedd4-mediated multiubiquitination of the insulin-like growth factor receptor regulates receptor internalization. J Cell Physiol 216:426-437.

Morrow EM, Yoo SY, Flavell SW, Kim TK, Lin Y, Hill RS, Mukaddes NM, Balkhy S, Gascon G, Hashmi A, Al-Saad S, Ware J, Joseph RM, Greenblatt R, Gleason D, Ertelt JA, Apse KA, Bodell A, Partlow JN, Barry $\mathrm{B}$, et al. (2008) Identifying autism loci and genes by tracing recent shared ancestry. Science 321:218-223.

Mosesson Y, Shtiegman K, Katz M, Zwang Y, Vereb G, Szollosi J, Yarden Y (2003) Endocytosis of receptor tyrosine kinases is driven by monoubiquitylation, not polyubiquitylation. J Biol Chem 278:21323-21326.

Mrkusich EM, Flanagan DJ, Whitington PM (2011) The core planar cell polarity gene prickle interacts with flamingo to promote sensory axon advance in the Drosophila embryo. Dev Biol 358:224-230.

Murakami Y, Matsufuji S, Kameji T, Hayashi SI, Igarashi K, Tamura T, Tanaka K, Ichihara A (1992) Ornithine decarboxylase is degraded by the 26S proteasome without ubiquitination. Nature 360:597-599.

Murray SS, Wong AW, Yang J, Li Y, Putz U, Tan SS, Howitt J (2019) Ubiquitin regulation of Trk receptor trafficking and degradation. Mol Neurobiol 56:1628-1636.

Myat A, Henry P, McCabe V, Flintoft L, Rotin D, Tear G (2002) Drosophila Nedd4, a ubiquitin ligase, is recruited by Commissureless to control cell surface levels of the roundabout receptor. Neuron 35:447-459.

$\mathrm{Na}$ CH, Jones DR, Yang Y, Wang X, Xu Y, Peng J (2012) Synaptic protein ubiquitination in rat brain revealed by antibody-based ubiquitome analysis. J Proteome Res 11:4722-4732.

Nagano Y, Yamashita H, Takahashi T, Kishida S, Nakamura T, Iseki E, Hattori N, Mizuno Y, Kikuchi A, Matsumoto M (2003) Siah-1 facilitates ubiquitination and degradation of synphilin-1. J Biol Chem 278:5150451514
Nakamuta S, Funahashi Y, Namba T, Arimura N, Picciotto MR, Tokumitsu H, Soderling TR, Sakakibara A, Miyata T, Kamiguchi H, Kaibuchi K (2011) Local application of neurotrophins specifies axons through inositol 1,4,5-trisphosphate, calcium, and $\mathrm{Ca}^{2+} /$ calmodulin-dependent protein kinases. Sci Signal 4:ra76.

Nakata K, Abrams B, Grill B, Goncharov A, Huang X, Chisholm AD, Jin Y (2005) Regulation of a DLK-1 and p38 MAP kinase pathway by the ubiquitin ligase RPM-1 is required for presynaptic development. Cell 120:407-420.

Nguyen LS, Schneider T, Rio M, Moutton S, Siquier-Pernet K, Verny F, Boddaert N, Desguerre I, Munich A, Rosa JL, Cormier-Daire V, Colleaux L (2016) A nonsense variant in HERC1 is associated with intellectual disability, megalencephaly, thick corpus callosum and cerebellar atrophy. Eur J Hum Genet 24:455-458.

Okumura F, Yoshida K, Liang F, Hatakeyama S (2011) MDA-9/syntenin interacts with ubiquitin via a novel ubiquitin-binding motif. Mol Cell Biochem 352:163-172.

Opperman KJ, Grill B (2014) RPM-1 is localized to distinct subcellular compartments and regulates axon length in GABAergic motor neurons. Neural Dev 9:10.

Opperman KJ, Mulcahy B, Giles AC, Risley MG, Birnbaum RL, Tulgren ED, Dawson-Scully K, Zhen M, Grill B (2017) The HECT family ubiquitin ligase EEL-1 regulates neuronal function and development. Cell Rep 19:822-835.

Osaka H, Wang YL, Takada K, Takizawa S, Setsuie R, Li H, Sato Y, Nishikawa K, Sun YJ, Sakurai M, Harada T, Hara Y, Kimura I, Chiba S, Namikawa K, Kiyama H, Noda M, Aoki S, Wada K (2003) Ubiquitin carboxy-terminal hydrolase L1 binds to and stabilizes monoubiquitin in neuron. Hum Mol Genet 12:1945-1958.

Packard M, Koo ES, Gorczyca M, Sharpe J, Cumberledge S, Budnik V (2002) The Drosophila Wnt, Wingless, provides an essential signal for pre- and postsynaptic differentiation. Cell 111:319-330.

Paemka L, Mahajan VB, Ehaideb SN, Skeie JM, Tan MC, Wu S, Cox AJ, Sowers LP, Gecz J, Jolly L, Ferguson PJ, Darbro B, Schneider A, Scheffer IE, Carvill GL, Mefford HC, El-Shanti H, Wood SA, Manak JR, Bassuk AG (2015) Seizures are regulated by ubiquitin-specific peptidase $9 \mathrm{X}$ linked (USP9X), a de-ubiquitinase. PLoS Genet 11:e1005022.

Peng J, Schwartz D, Elias JE, Thoreen CC, Cheng D, Marsischky G, Roelofs J, Finley D, Gygi SP (2003) A proteomics approach to understanding protein ubiquitination. Nat Biotechnol 21:921-926.

Perry G, Friedman R, Shaw G, Chau V (1987) Ubiquitin is detected in neurofibrillary tangles and senile plaque neurites of Alzheimer disease brains. Proc Natl Acad Sci USA 84:3033-3036.

Persaud A, Alberts P, Hayes M, Guettler S, Clarke I, Sicheri F, Dirks P, Ciruna B, Rotin D (2011) Nedd4-1 binds and ubiquitylates activated FGFR1 to control its endocytosis and function. EMBO J 30:3259-3273.

Petersen A, Honarvar A, Zetterberg M (2010) Changes in activity and kinetic properties of the proteasome in different rat organs during development and maturation. Curr Gerontol Geriatr Res 2010:1-9.

Pickart CM (2001) Mechanisms underlying ubiquitination. Annu Rev Biochem 70:503-533.

Pinto MJ, Almeida RD (2016) Puzzling out presynaptic differentiation. J Neurochem 139:921-942.

Pinto MJ, Alves PL, Martins L, Pedro JR, Ryu HR, Jeon NL, Taylor AM, Almeida RD (2016a) The proteasome controls presynaptic differentiation through modulation of an on-site pool of polyubiquitinated conjugates. J Cell Biol 212:789-801.

Pinto MJ, Pedro JR, Costa RO, Almeida RD (2016b) Visualizing K48 ubiquitination during presynaptic formation by ubiquitination-induced fluorescence complementation (UiFC). Front Mol Neurosci 9:43.

Piper RC, Dikic I, Lukacs GL (2014) Ubiquitin-dependent sorting in endocytosis. Cold Spring Harb Perspect Biol 6:a016808.

Po MD, Hwang C, Zhen M (2010) PHRs: bridging axon guidance, outgrowth and synapse development. Curr Opin Neurobiol 20:100-107.

Polleux F, Snider W (2010) Initiating and growing an axon. Cold Spring Harb Perspect Biol 2:a001925.

Polo S, Sigismund S, Faretta M, Guidi M, Capua MR, Bossi G, Chen H, De Camilli P, Di Fiore PP (2002) A single motif responsible for ubiquitin recognition and monoubiquitination in endocytic proteins. Nature 416:451-455.

Powis RA, Karyka E, Boyd P, Côme J, Jones RA, Zheng Y, Szunyogova E, Groen EJ, Hunter G, Thomson D, Wishart TM, Becker CG, Parson SH, 
Martinat C, Azzouz M, Gillingwater TH (2016) Systemic restoration of UBA1 ameliorates disease in spinal muscular atrophy. JCI Insight 1 : e87908.

Purro SA, Ciani L, Hoyos-Flight M, Stamatakou E, Siomou E, Salinas PC (2008) Wnt regulates axon behavior through changes in microtubule growth directionality: a new role for adenomatous polyposis coli. J Neurosci 28:8644-8654.

Ramser J, Ahearn ME, Lenski C, Yariz KO, Hellebrand H, von Rhein M, Clark RD, Schmutzler RK, Lichtner P, Hoffman EP, Meindl A, Baumbach-Reardon L (2008) Rare missense and synonymous variants in UBE1 are associated with X-linked infantile spinal muscular atrophy. Am J Hum Genet 82:188-193.

Riccomagno MM, Kolodkin AL (2015) Sculpting neural circuits by axon and dendrite pruning. Annu Rev Cell Dev Biol 31:779-805.

Rinetti GV, Schweizer FE (2010) Ubiquitination acutely regulates presynaptic neurotransmitter release in mammalian neurons. J Neurosci 30:31573166.

Rosso S, Bollati F, Bisbal M, Peretti D, Sumi T, Nakamura T, Quiroga S, Ferreira A, Cáceres A (2004) LIMK1 regulates Golgi dynamics, traffic of Golgi-derived vesicles, and process extension in primary cultured neurons. Mol Biol Cell 15:3433-3449.

Rotaru DC, van Woerden GM, Wallaard I, Elgersma Y (2018) Adult Ube3a gene reinstatement restores the electrophysiological deficits of prefrontal cortex layer 5 neurons in a mouse model of Angelman syndrome. J Neurosci 38:8011-8030

Rott R, Szargel R, Haskin J, Bandopadhyay R, Lees AJ, Shani V, Engelender S (2011) $\alpha$-Synuclein fate is determined by USP9X-regulated monoubiquitination. Proc Natl Acad Sci USA 108:18666-18671.

Russo A, Goel P, Brace EJ, Buser C, Dickman D, DiAntonio A (2019) The E3 ligase Highwire promotes synaptic transmission by targeting the NADsynthesizing enzyme dNmnat. EMBO Rep 20:e46975.

Ryu HW, Park CW, Ryu KY (2014) Restoration of cellular ubiquitin reverses impairments in neuronal development caused by disruption of the polyubiquitin gene Ubb. Biochem Biophys Res Commun 453:443-448.

Saiga T, Fukuda T, Matsumoto M, Tada H, Okano HJ, Okano H, Nakayama KI (2009) Fbxo45 forms a novel ubiquitin ligase complex and is required for neuronal development. Mol Cell Biol 29:3529-3543.

Saigoh K, Wang YL, Suh JG, Yamanishi T, Sakai Y, Kiyosawa H, Harada T, Ichihara N, Wakana S, Kikuchi T, Wada K (1999) Intragenic deletion in the gene encoding ubiquitin carboxy-terminal hydrolase in gad mice. Nat Genet 23:47-51.

Saliba RS, Michels G, Jacob TC, Pangalos MN, Moss SJ (2007) Activity-dependent ubiquitination of GABAA receptors regulates their accumulation at synaptic sites. J Neurosci 27:13341-13351.

Sasaki AT, Carracedo A, Locasale JW, Anastasiou D, Takeuchi K, Kahoud ER, Haviv S, Asara JM, Pandolfi PP, Cantley LC (2011) Ubiquitination of $\mathrm{K}$-Ras enhances activation and facilitates binding to select downstream effectors. Sci Signal 4:ra13.

Sehat B, Andersson S, Girnita L, Larsson O (2008) Identification of c-Cbl as a new ligase for insulin-like growth factor-I receptor with distinct roles from $\mathrm{Mdm} 2$ in receptor ubiquitination and endocytosis. Cancer Res 68:5669-5677.

Sepe M, Lignitto L, Porpora M, Delle Donne R, Rinaldi L, Belgianni G, Colucci G, Cuomo O, Viggiano D, Scorziello A, Garbi C, Annunziato L, Feliciello A (2014) Proteolytic control of neurite outgrowth inhibitor NOGO-A by the cAMP/PKA pathway. Proc Natl Acad Sci USA 111:15729-15734

Shi SH, Jan LY, Jan YN (2003) Hippocampal neuronal polarity specified by spatially localized mPar3/mPar6 and PI 3-kinase activity. Cell 112:63-75.

Shimamoto S, Kubota Y, Yamaguchi F, Tokumitsu H, Kobayashi R (2013) $\mathrm{Ca}^{2+} / \mathrm{S} 100$ proteins act as upstream regulators of the chaperone-associated ubiquitin ligase chip (c terminus of hsc70-interacting protein). J Biol Chem 288:7158-7168.

Shin JE, DiAntonio A (2011) Highwire regulates guidance of sister axons in the Drosophila mushroom body. J Neurosci 31:17689-17700.

Shin SM, Zhang N, Hansen J, Gerges NZ, Pak DT, Sheng M, Lee SH (2012) GKAP orchestrates activity-dependent postsynaptic protein remodeling and homeostatic scaling. Nat Neurosci 15:1655-1666.

Speese SD, Trotta N, Rodesch CK, Aravamudan B, Broadie K (2003) The ubiquitin proteasome system acutely regulates presynaptic protein turnover and synaptic efficacy. Curr Biol 13:899-910.
Stamenova SD, French ME, He Y, Francis SA, Kramer ZB, Hicke L (2007) Ubiquitin binds to and regulates a subset of SH3 domains. Mol Cell 25:273-284.

Stegmüller J, Konishi Y, Huynh MA, Yuan Z, Dibacco S, Bonni A (2006) Cell-intrinsic regulation of axonal morphogenesis by the Cdh1-APC target SnoN. Neuron 50:389-400.

Stoeckli ET (2018) Understanding axon guidance: are we nearly there yet? Dev 145:dev151415.

Südhof TC (2013) Neurotransmitter release: the last millisecond in the life of a synaptic vesicle. Neuron 80:675-690.

Sun AX, Yuan Q, Fukuda M, Yu W, Yan H, Lim GG, Nai MH, D'Agostino GA, Tran HD, Itahana Y, Wang D, Lokman H, Itahana K, Lim SW, Tang J, Chang YY, Zhang M, Cook SA, Rackham OJL, Lim CT, et al. (2019) Potassium channel dysfunction in human neuronal models of Angelman syndrome. Science 366:1486-1492.

Sun Q, Kelly GM (2010) Post-translational modification of CASK leads to its proteasome-dependent degradation. Int J Biochem Cell Biol 42:90-97.

Sun Y, Hu Z, Goeb Y, Dreier L (2013) The F-box protein MEC-15 (FBXW9) promotes synaptic transmission in GABAergic motor neurons in C. elegans. PLoS One 8:e59132.

Swaminathan S, Amerik AY, Hochstrasser M (1999) The Doa4 deubiquitinating enzyme is required for ubiquitin homeostasis in yeast. Mol Biol Cell 10:2583-2594.

Swatek KN, Komander D (2016) Ubiquitin modifications. Cell Res 26:399_ 422.

Tada H, Okano HJ, Takagi H, Shibata S, Yao I, Matsumoto M, Saiga T, Nakayama KI, Kashima H, Takahashi T, Setou M, Okano H (2010) Fbxo45, a novel ubiquitin ligase, regulates synaptic activity. J Biol Chem 285:3840-3849.

Tai HC, Schuman EM (2008) Ubiquitin, the proteasome and protein degradation in neuronal function and dysfunction. Nat Rev Neurosci 9:826838.

Tanaka K (2013) The proteasome: from basic mechanisms to emerging roles. Keio J Med 62:1-12.

Tao H, Manak JR, Sowers L, Mei X, Kiyonari H, Abe T, Dahdaleh NS, Yang T, Wu S, Chen S, Fox MH, Gurnett C, Montine T, Bird T, Shaffer LG, Rosenfeld JA, McConnell J, Madan-Khetarpal S, Berry-Kravis E, Griesbach H, et al. (2011) Mutations in prickle orthologs cause seizures in flies, mice, and humans. Am J Hum Genet 88:138-149.

Thrower JS, Hoffman L, Rechsteiner M, Pickart CM (2000) Recognition of the polyubiquitin proteolytic signal. EMBO J 19:94-102.

Tonazzini I, Van Woerden GM, Masciullo C, Mientjes EJ, Elgersma Y, Cecchini M (2019) The role of ubiquitin ligase E3A in polarized contact guidance and rescue strategies in UBE3A-deficient hippocampal neurons. Mol Autism 10:41.

Trujillo G, Nakata K, Yan D, Maruyama IN, Jin Y (2010) A ubiquitin E2 variant protein acts in axon termination and synaptogenesis in Caenorhabditis elegans. Genetics 186:135-145.

Tursun B, Schlüter A, Peters MA, Viehweger B, Ostendorff HP, Soosairajah J, Drung A, Bossenz M, Johnsen SA, Schweizer M, Bernard O, Bach I (2005) The ubiquitin ligase Rnf6 regulates local LIM kinase 1 levels in axonal growth cones. Genes Dev 19:2307-2319.

Uthaman SB, Godenschwege TA, Murphey RK (2008) A mechanism distinct from highwire for the Drosophila ubiquitin conjugase bendless in synaptic growth and maturation. J Neurosci 28:8615-8623.

Utine GE, Taş kıran EZ, Koş ukcu C, Karaosmanoğlu B, Güleray N, Doğan ÖA, Kiper PÖ, Boduroğlu K, Alikaşifoğlu M (2017) HERC1 mutations in idiopathic intellectual disability. Eur J Med Genet 60:279-283.

Valnegri P, Huang J, Yamada T, Yang Y, Mejia LA, Cho HY, Oldenborg A, Bonni A (2017) RNF8/UBC13 ubiquitin signaling suppresses synapse formation in the mammalian brain. Nat Commun 8:1271.

Vandewalle J, Langen M, Zschätzsch M, Nijhof B, Kramer JM, Brems H, Bauters M, Lauwers E, Srahna M, Marynen P, Verstreken P, Schenck A, Hassan BA, Froyen G (2013) Ubiquitin ligase HUWE1 regulates axon branching through the Wnt/ $\beta$-catenin pathway in a Drosophila model for intellectual disability. PLoS One 8:e81791.

van Leeuwen FW, de Kleijn DP, van den Hurk HH, Neubauer A, Sonnemans MA, Sluijs JA, Köycü S, Ramdjielal RD, Salehi A, Martens GJ, Grosveld FG, Peter J, Burbach H, Hol EM (1998) Frameshift mutants of $\beta$ amyloid precursor protein and ubiquitin-B in Alzheimer's and Down patients. Science 279:242-247. 
van Roessel P, Elliott DA, Robinson IM, Prokop A, Brand AH (2004) Independent regulation of synaptic size and activity by the anaphase-promoting complex. Cell 119:707-718.

Vecchione A, Marchese A, Henry P, Rotin D, Morrione A (2003) The Grb10/Nedd4 complex regulates ligand-induced ubiquitination and stability of the insulin-like growth factor I receptor. Mol Cell Biol 23:33633372 .

Verma R, Oania R, Graumann J, Deshaies RJ (2004) Multiubiquitin chain receptors define a layer of substrate selectivity in the ubiquitin-proteasome system. Cell 118:99-110.

Waites CL, Leal-Ortiz SA, Okerlund N, Dalke H, Fejtova A, Altrock WD, Gundelfinger ED, Garner CC (2013) Bassoon and Piccolo maintain synapse integrity by regulating protein ubiquitination and degradation. EMBO J 32:954-969.

Wakatsuki S, Saitoh F, Araki T (2011) ZNRF1 promotes Wallerian degeneration by degrading AKT to induce GSK3B-dependent CRMP2 phosphorylation. Nat Cell Biol 13:1415-1423.

Wakatsuki S, Tokunaga S, Shibata M, Araki T (2017) GSK3B-mediated phosphorylation of MCL1 regulates axonal autophagy to promote Wallerian degeneration. J Cell Biol 216:477-493.

Walden H, Rittinger K (2018) RBR ligase-mediated ubiquitin transfer: a tale with many twists and turns. Nat Struct Mol Biol 25:440-445.

Wallace ML, Burette AC, Weinberg RJ, Philpot BD (2012) Maternal loss of Ube3a produces an excitatory/inhibitory imbalance through neuron type-specific synaptic defects. Neuron 74:793-800.

Wan HI, DiAntonio A, Fetter RD, Bergstrom K, Strauss R, Goodman CS (2000) Highwire regulates synaptic growth in Drosophila. Neuron 26:313-329.

Wang C, Deng L, Hong M, Akkaraju GR, Inoue JI, Chen ZJ (2001) TAK1 is a ubiquitin-dependent kinase of MKK and IKK. Nature 412:346-351.

Wang J, Peng Q, Lin Q, Childress C, Carey D, Yang W (2010) Calcium activates Nedd4 E3 ubiquitin ligases by releasing the C2 domain-mediated auto-inhibition. J Biol Chem 285:12279-12288.

Wang PY, Lin YM, Wang LH, Kuo TY, Cheng SJ, Wang GS (2017) Reduced cytoplasmic MBNL1 is an early event in a brain-specific mouse model of myotonic dystrophy. Hum Mol Genet 26:2247-2257.

Wang PY, Chang KT, Lin YM, Kuo TY, Wang GS (2018) Ubiquitination of MBNL1 is required for its cytoplasmic localization and function in promoting neurite outgrowth. Cell Rep 22:2294-2306.

Wang Z, Hou Y, Guo X, van der Voet M, Boxem M, Dixon JE, Chisholm AD, Jin Y (2013) The EBAX-type Cullin-RING E3 ligase and Hsp90 guard the protein quality of the SAX-3/Robo receptor in developing neurons. Neuron 79:903-916.

Watts RJ, Hoopfer ED, Luo L (2003) Axon pruning during Drosophila metamorphosis: evidence for local degeneration and requirement of the ubiquitin-proteasome system. Neuron 38:871-885.

Wenzel DM, Lissounov A, Brzovic PS, Klevit RE (2011) UBCH7 reactivity profile reveals parkin and HHARI to be RING/HECT hybrids. Nature 474:105-108.

Wheeler TC, Chin LS, Li Y, Roudabush FL, Li L (2002) Regulation of synaptophysin degradation by mammalian homologues of seven in absentia. J Biol Chem 277:10273-10282.

Widagdo J, Chai YJ, Ridder MC, Chau YQ, Johnson RC, Sah P, Huganir RL, Anggono V (2015) Activity-dependent ubiquitination of GluA1 and GluA2 regulates AMPA receptor intracellular sorting and degradation. Cell Rep 10:783-795.

Williams EJ, Furness J, Walsh FS, Doherty P (1994) Activation of the FGF receptor underlies neurite outgrowth stimulated by L1, N-CAM, and Ncadherin. Neuron 13:583-594.

Wilson SM, Bhattacharyya B, Rachel RA, Coppola V, Tessarollo L, Householder DB, Fletcher CF, Miller RJ, Copeland NG, Jenkins NA (2002) Synaptic defects in ataxia mice result from a mutation in Usp14, encoding a ubiquitin-specific protease. Nat Genet 32:420-425.

Windheim M, Stafford M, Peggie M, Cohen P (2008) Interleukin-1 (IL-1) induces the Lys63-linked polyubiquitination of IL-1 receptor-associated kinase 1 to facilitate NEMO binding and the activation of $\mathrm{I} \kappa \mathrm{B} \alpha$ kinase. Mol Cell Biol 28:1783-1791.

Wishart TM, Mutsaers CA, Riessland M, Reimer MM, Hunter G, Hannam ML, Eaton SL, Fuller HR, Roche SL, Somers E, Morse R, Young PJ,
Lamont DJ, Hammerschmidt M, Joshi A, Hohenstein P, Morris GE, Parson SH, Skehel PA, Becker T, et al. (2014) Dysregulation of ubiquitin homeostasis and $\beta$-catenin signaling promote spinal muscular atrophy. J Clin Invest 124:1821-1834

Wolf B, Seeger MA, Chiba A (1998) Commissureless endocytosis is correlated with initiation of neuromuscular synaptogenesis. Development 125:3853-3863.

Wong JJ, Li S, Lim EK, Wang Y, Wang C, Zhang H, Kirilly D, Wu C, Liou YC, Wang H, Yu F (2013) A Cullin1-based SCF E3 ubiquitin ligase targets the InR/PI3K/TOR pathway to regulate neuronal pruning. PLoS Biol 11:e1001657.

Wu C, Daniels RW, DiAntonio A (2007) DFsn collaborates with Highwire to down-regulate the Wallenda/DLK kinase and restrain synaptic terminal growth. Neural Dev 2:16.

Xiong X, Hao Y, Sun K, Li J, Li X, Mishra B, Soppina P, Wu C, Hume RI, Collins CA (2012) The Highwire ubiquitin ligase promotes axonal degeneration by tuning levels of Nmnat protein. PLoS Biol 10:e1001440.

Xu P, Duong DM, Seyfried NT, Cheng D, Xie Y, Robert J, Rush J, Hochstrasser M, Finley D, Peng J (2009) Quantitative proteomics reveals the function of unconventional ubiquitin chains in proteasomal degradation. Cell 137:133-145.

Yamagishi Y, Tessier-Lavigne M (2016) An atypical SCF-like ubiquitin ligase complex promotes Wallerian degeneration through regulation of axonal Nmnat2. Cell Rep 17:774-782.

Yan D, Guo L, Wang Y (2006) Requirement of dendritic Akt degradation by the ubiquitin-proteasome system for neuronal polarity. J Cell Biol 174:415-424.

Yang SW, Oh KH, Park E, Chang HM, Park JM, Seong MW, Ka SH, Song WK, Park DE, Baas PW, Jeon YJ, Chung CH (2013) USP47 and C terminus of Hsp70-Interacting protein (CHIP) antagonistically regulate katanin-p60-mediated axonal growth. J Neurosci 33:12728-12738.

Yang Y, Kim AH, Yamada T, Wu B, Bilimoria PM, Ikeuchi Y, de la Iglesia N, Shen J, Bonni A (2009) A Cdc20-APC ubiquitin signaling pathway regulates presynaptic differentiation. Science 326:575-578.

Yang Y, Kim AH, Bonni A (2010) The dynamic ubiquitin ligase duo: cdh1APC and Cdc20-APC regulate neuronal morphogenesis and connectivity. Curr Opin Neurobiol 20:92-99.

Yao I, Takagi H, Ageta H, Kahyo T, Sato S, Hatanaka K, Fukuda Y, Chiba T, Morone N, Yuasa S, Inokuchi K, Ohtsuka T, Macgregor GR, Tanaka K, Setou M (2007) SCRAPPER-dependent ubiquitination of active zone protein RIM1 regulates synaptic vesicle release. Cell 130:943-957.

Yashiro K, Riday TT, Condon KH, Roberts AC, Bernardo DR, Prakash R, Weinberg RJ, Ehlers MD, Philpot BD (2009) Ube3a is required for experience-dependent maturation of the neocortex. Nat Neurosci 12:777-783.

Yogev S, Shen K (2017) Establishing neuronal polarity with environmental and intrinsic mechanisms. Neuron 96:638-650.

Yuasa-Kawada J, Kinoshita-Kawada M, Wu G, Rao Y, Wu JY (2009) Midline crossing and Slit responsiveness of commissural axons require USP33. Nat Neurosci 12:1087-1089.

Zang S, Ali YO, Ruan K, Zhai RG (2013) Nicotinamide mononucleotide adenylyltransferase maintains active zone structure by stabilizing Bruchpilot. EMBO Rep 14:87-94.

Zhang Q, Li Y, Zhang L, Yang N, Meng J, Zuo P, Zhang Y, Chen J, Wang L, Gao X, Zhu D (2013) E3 ubiquitin ligase RNF13 involves spatial learning and assembly of the SNARE complex. Cell Mol Life Sci 70:153-165.

Zhang Y, Gao J, Chung KK, Huang H, Dawson VL, Dawson TM (2000) Parkin functions as an E2-dependent ubiquitin-protein ligase and promotes the degradation of the synaptic vesicle-associated protein, CDCrel1. Proc Natl Acad Sci USA 97:13354-13359.

Zhao Y, Hegde AN, Martin KC (2003) The ubiquitin proteasome system functions as an inhibitory constraint on synaptic strengthening. Curr Biol 13:887-898.

Zheng N, Shabek N (2017) Ubiquitin ligases: structure, function, and regulation. Annu Rev Biochem 86:129-157.

Zhu Q, Dong H, Bukhari AA, Zhao A, Li M, Sun Y, Zhang X, Cao C, Su D, Liang X (2020) HUWE1 promotes EGFR ubiquitination and degradation to protect against renal tubulointerstitial fibrosis. FASEB J 34:4591-4601. 